\title{
Analysis of Connectivity in the Cat Cerebral Cortex
}

\author{
Jack W. Scannell, Colin Blakemore, and Malcolm P. Young \\ University Laboratory of Physiology, Oxford OX1 3PT, United Kingdom
}

The mammalian cerebral cortex is innervated by a large number of corticocortical connections. The number of connections makes it difficult to understand the organization of the cortical network. Nonetheless, conclusions about the organization of cortical systems drawn from examining connectional data have often been made in a speculative and informal manner, unsupported by any analytic treatment. Recently, progress has been made toward more systematic ways of extracting organizing principles from data on the network of connections between cortical areas of the monkey. In this article, we extend these approaches to the cortical systems of the cat.

We collated information from the neuroanatomical literature about the corticocortical connections of the cat. This collation incorporated 1139 reported corticocortical connections between 65 cortical areas. We have previously used an optimization technique (Scannell and Young, 1993) to analyze this database in order to represent the connectional organization of cortical systems in the cat. Here, we report the connectional database and analyze it in a number of further ways. First, we employed rules from Felleman and Van Essen (1991) to investigate hierarchical relations among the areas. Second, we compared quantitatively the results of the optimization method with the results of the hierarchical method. Third, we examined quantitatively whether simple connection rules, which may reflect the development and evolution of the cortex, can account for the experimentally identified corticocortical connections in the database.

The results showed, first, that hierarchical rules, when applied to the cat visual system, define a largely consistent hierarchy. Second, in both auditory and visual systems, the ordering of areas by hierarchical analysis and by optimization analysis was statistically significantly related. Hence, independent analyzes concur broadly in their ordering of areas in the cortical hierarchies. Third, the majority of corticocortical connections, and much of the pattern of connectivity, were accounted for by a simple "nearest-neighbor-or-next-door-but-one" connection rule, which may suggest one of the mechanisms by which the development of cortical connectivity is controlled.

[Key words: cat, cortex, corticocortical connections, op-

\footnotetext{
Received Feb. 9, 1994; revised June 30, 1994; accepted Aug. 22, 1994.

This work was supported by the MRC, the Oxford McDonnell-Pew Centre for Cognitive Neuroscience, a SERC graduate award to J.W.S., and by a Royal Society University Research Fellowship for M.P.Y. We thank Mark O'Neil and Phil Benson for computer support.

Correspondence should be addressed to Malcolm P. Young, Department of Biology, Ridley Building, University of Newcastle, Newcastle-upon-Tyne, NE1 7RU, UK

Copyright $(\mathcal{C} 1995$ Society for Neuroscience $0270-6474 / 95 / 151463-21 \$ 05.00 / 0$
}

timization, multidimensional scaling, hierarchy, neighborhood wiring, topology, vision, auditory, somatosensory, motor, frontal, limbic]

Neuroanatomical studies have revealed a large number of connections linking different brain structures. The corticocortical connections, although only a subset of these connections, form a network of such complexity that intuitive understanding of its organization is very difficult. Analysis of neuroanatomical connection data is required to substantiate the many informal speculations about neural organization that have been drawn from it.

Several principled approaches to analysis of connection data have been described: hierarchical analysis (Rockland and Pandya, 1979; Maunsell and Van Essen, 1983; Felleman and Van Essen, 1991;), cluster analysis (Musil and Olson, 1991), and, more recently, an optimization approach using nonmetric multidimensional scaling (NMDS) (Scannell et al., 1992; Young, 1992a-c, 1993; Scannell and Young, 1993). These techniques derive numerical descriptions of the organization of the network from neuroanatomical connection data.

Hierarchical analysis classifies connections as ascending, descending, or lateral, according to their patterns of laminar origin and termination. The directions of the connections are then used to place areas above, helow, or at the same level in a unidimensional hierarchy. The optimization approach (Young, 1992a-c, 1993) analyzes a matrix of connections between brain structures with NMDS (Shepard, 1962, 1980), minimizing the distance between connected structures and, at the same time, maximizing the distance between structures that have no reported interconnection. The analysis results in a nonarbitrary topological structure that represents the organization of a brain system in a spatial framework by placing areas with very similar patterns of connections close together, and areas with very different connection patterns far apart. In contrast to alternative representations of corticocortical connectivity (e.g., Table 1), the topological diagrams produced by NMDS can be relatively easy to understand, and may provide insights into the organization of a system that are not obvious intuitivcly.

Both topological diagrams and hierarchical structures are mathematically tractable. In this article, we compare quantitatively the results of optimization and hierarchical analyses. We also compare quantitatively what is known of the connectional organization of the cortex with the connections that would result if simple connection rules operated during the development of the cortical network.

\section{Materials and Methods}

Cortical parcellation. There is no universally agreed parcellation scheme for the cat cortex. The parcellation that we used was utilitarian: we endeavored to take account of good connection data for the connections between the greatest number of cortical areas. Where possible, 
we included areas commonly found in the neurophysiological and neuroanatomical literature (see Appendix). We expect the parcellation scheme to evolve and improve as more information becomes available. Our cortical map was based principally on the parcellation presented by Cavada and Reinoso-Suarez (1985). It was supplemented by maps for the auditory system taken from Imig and Reale (1980), for areas 4, 5, and 6 from Avendano and Rausell (1988), for the parahippocampal regions from Room and Groenewegen (1986a,b) and Krettek and Price (1977a,b), and for the visual system from Symmonds and Rosenquist (1984a), Rosenquist (1985), and Tusa et al. (1979).

It was sometimes necessary to compromise between high-resolution cytoarchitectonic parcellations, such as the division of area 6 into $6 \mathrm{a} \alpha$, $6 \mathrm{a} \beta$, and 6if (see Avendano and Rausell, 1988), and the need to find sufficient connections described in the literature that could be fitted into the parcellation scheme. Most connectional studies, for example, have not distinguished between these cytoarchitectonic divisions of area 6 . For this reason, we parcelled this region into medial and lateral parts rather than into strict cytoarchitectonic regions.

Areas in this scheme are not necessarily discrete physiological entities. For example, Sherk (1986) and Grant and Shipp (1991) consider that PMLS and at least parts of VLS and AMLS belong to a single field, the Clare-Bishop area (Clare and Bishop, 1954; Hubel and Wiesel, 1969), while Symmonds and Rosenquist (1984a) and Palmer et al. (1978) consider them distinct areas. Analysis, however, can itself inform this issue, since areas that have the same pattern of connections and, therefore, probably constitute a single functional field, will occupy identical positions in diagrams derived by NMDS

Just as some of the areas in our parcellation scheme may not be discrete physiological areas, others may contain more than one physiological area and cannot be regarded as a homogenous wholc. For example, the medial part of area $6,6 \mathrm{~m}$, contains a number of cytoarchitectonic regions and physiological areas (Nakai et al., 1986; Avendano and Rausell, 1988). Some other cortical areas are known to have subcompartments with different patterns of connections (e.g., Zeki and Shipp, 1991). We did not resolve the connections of these subcompartments here because there is insufficiently detailed information available about their connectivity, but there is no reason why they could not be included when more data become available. We regard our cortical parcellation scheme as a "working model," and expect it to change as knowledge of the identity and location of cortical areas improves.

Collation of connection data. We produced a database of corticocortical connections from information in the following anatomical studies, Alloway and Burton (1985), Avendano and Rausell (1988), Battaglini et al. (1980), Babb et al. (1984), Berson and Graybiel (1981), Blakemore and Zumbroich (1987), Bowman and Olson (1988), Brugge and Reale (1984), Burton and Kopf (1984), Burton et al. (1982), Cavada (1984), Cavada et al. (1983), Cavada and Reinoso-Suarez (1981, 1983, 1985), Clarey and Irvine (1986, 1990a,b), Dykes (1978), Dykes and Ruest (1986), Dykes et al. (1980), Ferrer et al. (1988), Gilbert and Kelly (1975), Grant and Shipp (1991), Grant et al. (1984), Graziosi et ai. (1982), Guildin and Markowitsch (1984), Guildin et al. (1986), Heath and Jones (1971), Irle and Markowitsch (1982), Imig and Reale (1980), Ino et al. (1990), Jones and Powell $(1968,1973)$, Kawamura (1973ac), Kawamura and Naito (1980), Krettek and Price (1977a,b), Kuchiiwa et al. (1985), Llamas et al. (1985), Macchi et al. (1978), Maciewicz (1974), McNair and Avendano (1980), Micelli et al. (1985), Minciacchetti et al. (1987), Morel and Imig (1987), Mori et al. (1989), Mucke et al. (1982), Musil and Olson (1986, 1988a,b), Nakai et al. (1986), Norita et al. (1986), Olson and Edelstein (1984), Olson and Graybiel (1987), Olson and Jeffers (1987), Olson and Lawler (1987), Paula-Barbossa et al. (1975), Perez-Bas et al. (1985), Porter (1991), Porter and Sakamoto (1988), Price and Blakemore (1985), Price (1985), Price and Zumbroich (1989), Reinoso-Suarez (1984), Reinoso-Suarez and Roda (1985), Rosenquist (1985), Rouiller et al. (1990, 1991), Room and Groenewegen (1986a,b), Room et al. (1985), Russchen (1982), Sherk (1986), Shipp and Grant (1991), Squatrito et al. (1981a-c), Symonds and Rosenquist (1984a,b), Updike (1982, 1986), Van Groen and Lopes da Silva (1986), Van Groen et al. (1986), Van Groen and Wyss (1988), Vedovato (1978), Waters et al. (1982), Winguth and Winer (1989), Witter and Groenewegen (1984, 1986a), Witter et al. (1986), Yamaguchi et al. (1982), Yumiya and Ghez (1984), Zarzeki et al. (1978).

The full database, on which the analyses presented here are based, is available in ASCII format by anonymous FTP (ftp crick. physiology.ox.ac.uk; user name $=$ anonymous; password $=$ your email address; directory = pub; filename = cat_conn.txt).
We used five criteria to assign connections to our database, as follows.

(1) Only data from the cat were used. No extrapolations were made from structures thought to be homologous in other animals.

(2) Evidence for connections was taken either from text or figures when it could be fitted unequivocally to our cortical map.

(3) We gave priority in assigning connection strengths to data from higher resolution studies. For example, Avendano and Rausell (1988) report afferent connections to seven subdivisions of area 5. Most reports of the efferent projections of area 5 do not have this level of resolution. If, for example, an area was known to project only to $5 \mathrm{bl}$ but reported, in another study, to receive projections from "area 5," then it was assumed that these originated from $5 \mathrm{bl}$.

(4) We assumed the least necessary number of connections. If one study identified a connection at low spatial resolution (that is, it could not be assigned uniquely to one of our areas) and other studies identified the connection at a higher resolution, the connection would only be assigned to the areas with which it was described at higher resolution. For example, Cavada and Reinoso-Suarez (1983) considered the connections of area 20 as a whole, while Symmonds and Rosenquist $(1984 \mathrm{a}, \mathrm{b})$ divide area 20 into $20 \mathrm{a}$ and $20 \mathrm{~b}$. If a connection demonstrated for area 20 in one study had also been demonstrated for 20 a but not for $20 \mathrm{~b}$ in another, then that connection was assumed to be with area 20 a only.

(5) Where a connection could not be assigned unambiguously to one of our areas, for example a connection to the "perirhinal area," it was assigned to those areas in our map that fell within the area stated in the original reference. A connection to the "perirhinal area" would be assigned to both areas 35 and 36 if no other evidence were available.

We recorded (1) the presence or absence of a connection, (2) its strength or density, and where information was available, (3) the laminar origin and termination of a connection. Connections that were reported as dense or strong were given a strength weighting of 3 ; weak or sparse connections were weighted as 1 ; and connections of intermediate strength, or for which no strength information was available, were weighted as 2 . We assumed that descriptions of the density of projections as strong, moderate, or weak made in different studies were equivalent, that is, that possible differences in the amounts of tracer or different methods of visualization did not substantially alter the classification of the strengths of connections. No distinction was made between connections that have been activcly looked for and reported absent, and connections that have simply not been reported. The apparent absence of a connection is a finding of no effect, and rather than assuming that some findings of no effect are more important than others, we treated all unreported connections equally and gave them a weight of 0 . A quantitative treatment of this issue can be found in Young (1992a), in which different coding strategies for unreported connections were compared and found to yield very similar results.

There are practical difficulties in collating data from a large number of neuroanatomical tracing studies, particularly as different studies do not always produce congruent results. We advise that the original sources should be consulted before uncritically accepting any specific connection presented in this article.

Optimization methods. The connection matrices were analyzed with an optimization method, nommetric multidimensional scaling (NMDS) (Shepard, 1962; Takane et al., 1977; Young et al., 1978; Young, 1987; Young and Harris, 1990), which has been applied to the corticocortical connections of the monkey (Young, 1992a-c, 1993) and of the cat (Scannell et al., 1992; Scannell and Young, 1993).

The analysis works in the following way. Imagine that we have a disordered collection of boxes, some of which are connected by pieces of elastic. One way to uncover the connectional organization of the hoxes is to rearrange the boxes according to two rules. First, all the pieces of elastic should be as short as possible, and second, unconnected boxes should be as far apart as possible. If the boxes are connected in a simple linear order (i.c., a hicrarchy), then they will come to lie in a line. If the connections between the boxes are more complex, because boxes are sometimes connected to more than just their neighbors in the line, but there is still a broadly hierarchical connection pattern, then the boxes will still be stretched out by these two rules into a line, but the line will be curved. The curvature comes about because boxes "early" in the line will be closer to boxes "late" in the line than if the boxes formed a simple serial hierarchy. It is of note that systems that exhibit straight or curved lines when analyzed by these rules can be hierarchical on purely topological grounds; that is, the analysis can reveal hierar- 
chical structure without any consideration of laminar termination patterns.

These rules, that the distance between connected structures should be minimized and at the same time the distance between unconnected structures maximized, can respect almost any connection pattern between a set of elements. They do this by placing those elements that have a similar connection pattern close together and those with a different pattern of connections far apart. This is important because connection patterns in real brains may not, of course, form hierarchies. If the boxes are connected in some heterarchy, for example, then the application of these constraints will arrange them into a configuration that respects their pattern of connections, by placing connectionally associated elements together. Young (1993) demonstrated an example of such nonhierarchical structures present in a network: an analysis of connections between almost all cortical areas of the monkey showed four distinct clusters of areas that corresponded to the visual, auditory, somatosensory-motor systems, and a "frontolimbic" complex.

If the arrangement of boxes by these rules were restricted to a twodimensional plane, some connections might be between boxes that were constrained by many other connections to be far apart. Such poorly fitted connections would be better accounted for if the arrangement of the elements took place in three dimensions. Addition of a fourth dimension would account even better for the connection pattern. Indeed, if there were sufficient dimensions in which to distribute the elements, all connections could be well reflected in the arrangement of the elements: all connected structures would be very close and all unconnected elements would be very far apart. The entries in a connection matrix are, thus, measures of the proximity of each pair of elements in such a high-dimensional space. In fact, the connection matrix and the distribution of the elements in a multivariate space can be computed from one another: they are interchangeable descriptions. The problem of representing the topological organization of the elements in an understandable way is, hence, just the problem of dimensional reduction: that of mapping from a high-dimensional arrangement to an understandable low-dimensional arrangement that captures as much of the variability as possible. NMDS, a powerful statistical tool, performs exactly this operation (Shepard, 1962; Takane et al., 1977; Young et al., 1978; Young, 1987; Young and Harris, 1990).

A diagram representing a structure that best fits the connectional topology of alnosi any neural systen, in a sinall number of dimensions, can be computed by NMDS. In such a structure, the positions of areas are specified by being ones that minimize the distance between connected areas and at the same time maximize the distance between areas that are not connected. The analysis, thus, represents in a spatial framework the organizational structure of the network of corticocortical connections between the analyzed brain regions.

Structures were derived by submitting a connection matrix to NMDS, using the widely available ALSCAL program in the SPSSX statistical package (Young and Harris, 1990). Solutions with the level of measurement specified as nominal and ordinal were derived, to assess whether the data needed to be conditioned by a least-squares categorical transformation before analysis. In no case were there perceptible differences between them, and ordinal solutions are the ones reported. We took the primary approach to ties because analysis of sparse, low-level test data showed this approach to recover data structure more reliably. To avoid the problem of the optimization procedure becoming stalled in local minima, both shuffled and symmetrical versions of the input matrix were used to produce ordinal solutions in one to six dimensions. The solutions of the shuffled and symmetrical matrices were compared using Procrustes rotation (see below), and in the rare cases of perceptible differences between them, lower variance-explained solutions were discarded. Solutions with different dimensionality were compared. These comparisons showed that solutions in numbers of dimensions greater than 2 typically did not show large increases in the amount of variability explained. We examined structures derived by specifying an ordinal level of measurement in two and three dimensions. In no case did the 3D solutions vary with shuffling of the input matrix. The 3D solutions were visualized using computer graphics, and were consistent with all aspects of the two-dimensional solutions reported here and elsewhere (e.g.. Scannell and Young, 1993).

The resulting topological diagrams are optimal $2 \mathrm{D}$ representations of the pattern of connections, in that the proximities of the points representing cortical areas are optimally close to the rank order of the proximities (i.e., connection strengths) in the connection matrix. The con- figuration is the optimal 2D arrangement in which strong connections are shorter than intermediate connections, which are shorter than wcak connections, which are, in turn, shorter than nonconnections. The topological analyses here included no information about the connectivity of the cortical areas with subcortical structures, nor about corticocortical connections with the contralateral cerebral hemisphere. Nonetheless, this type of analysis can be extended to encompass these additional data.

Quantitative comparisons-Procrustes rotation and approximate randomization. We used a regression-like procedure, Procrustes rotation (Schonemann and Carroll, 1970; Gower, 1971), which is implemented in the widely available GENSTAT statistical programming language, to make quantitative comparisons between structures. Procrustes rotation can compare structures in any number of dimensions, by reflecting, rotating, and scaling them to produce an optimal fit. After finding the optimal transformation that maps one structure onto another, the procedure yields a variance-explained statistic that reflects the goodnessof-fit between the two models. The statistical rarity of each comparison was evaluated by an approximate randomization test (Edgington, 1980). This test repeated the Procrustes rotation with one of the structures shuffled randomly on each of 600 iterations. The number of times that the variance-explained statistic was exceeded during these random iterations was divided by the number of iterations to give a probability statistic that a correspondence as good as the particular comparison could have come about by chance (Edgington, 1980). Each varianceexplained statistic $\left(r^{2}\right)$ value can be converted into a correlation coefficient by calculating its squarc root.

Hierarchical analysis. Rockland and Pandya (1979), Maunsell and Van Essen (1983), and Felleman and Van Essen (1991) have developed a method for defining the hierarchical arrangement of a set of cortical areas based on the laminar origins and terminations of the connections linking them. In a recent review of the macaque visual system, Felleman and Van Essen (1991) gave criteria by which corticocortical connections can be classified as ascending, descending, and lateral. Ascending projections originate in the supragranular or supragranular and infragranular layers and terminate predominantly in layer 4 . Lateral projections originate in a bilaminar pattern from both the supra- and infragranular layers and terminate throughout the thickness of the cortex, often in a columnar pattern. Descending projections originate bilaminarly or in the infragranular layers and terminate in the superficial supragranular and/ or deep infragranular layers.

Models of the hierarchical organization of the cat visual system were computed from data in our connectional database and taken from Felleman and Van Essen (1991). A model of the hierarchical organization of the cat auditory system was taken from Rouiller et al. (1991). Procrustes rotation was used to compare the hierarchies with topological structures including the corresponding areas.

Simple connection models. We used our map of the areas of the cat cortex (Fig. 1) to produce matrices of the corticocortical connections that would occur if two simple neighborhood-connection rules controlled the development of cortical connections. The first matrix, the nearest-neighbor model, was derived by scoring hypothetical connections between areas that share a common border as 1 and all other possible connections as 0 . A second matrix, the nearest-neighbor-ornext-door-but-one model, was derived by assuming that neighboring areas have strong connections (a weight of 3 ), that areas with more than one nearest neighbor in common have moderate connections (a weight of 2), and that areas sharing one nearest neighbor have weak connections (a weight of 1 ).

The simple connection model matrices were analyzed in two ways. In the first type of analysis, we directly compared the connections revealed by the literature survey with those predicted by simple connection rules. To visualize the comparison, matrices were produccd that illustrated the real anatomical connectivity of the cortex (e.g., Figs. 4, 5). Experimentally identified connections accounted for by the simple models (called hits) were colored gray, while connections for which the models did not account (misses) were black. We also produced matrices to illustrate the connections predicted by the simple connection models (Figs. 6, 7). Model connections that coincided with connections reported in the real brain (hits) were drawn in gray, and model connections that are not present, or have not been demonstrated in the real brain (misses), were black. These comparisons did not distinguish the strength of the connections. In the second type of analysis, NMDS was applied to the model matrices to derive configurations analogous to the topological structures derived from real con- 


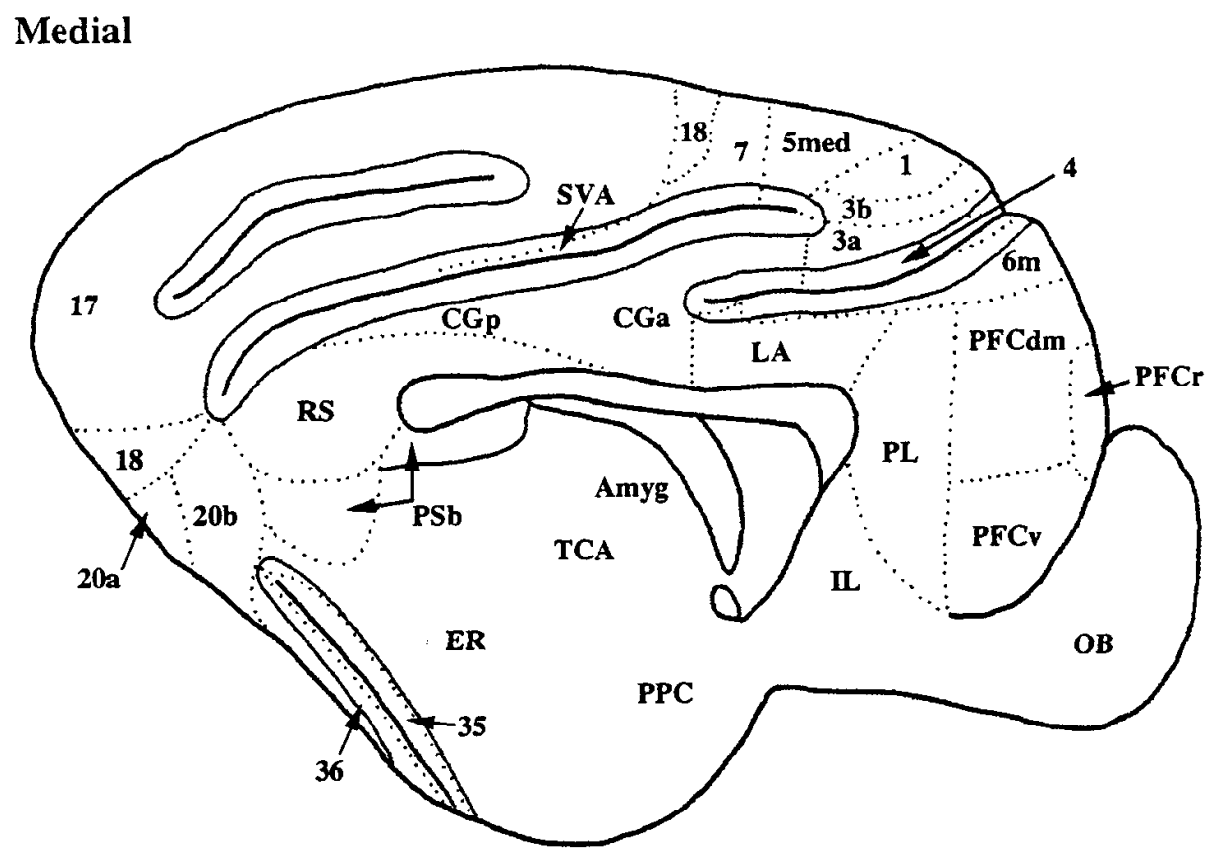

Figure I. Parcellation of the cat cortex. All the areas shown on the map were included in the collation and analysis, with the exception of TCA (corticoamygdaloid transition area), $P P C$ (prepiriform cortex), and $O B$ (olfactory bulb). The hippocampus and subiculum are not shown. The parcellation was based on Krettek and Price (1977a,b), Tusa et al. (1979), Imig and Reale (1984), Reinoso-Suarez (1984), Symmonds and Rosenquist (1984a), Cavada et al. (1985), Rosenquist (1985), and Avendano and Raussell (1988). Details of the areas and their relation to other parcellation schemes are given in the Appendix.

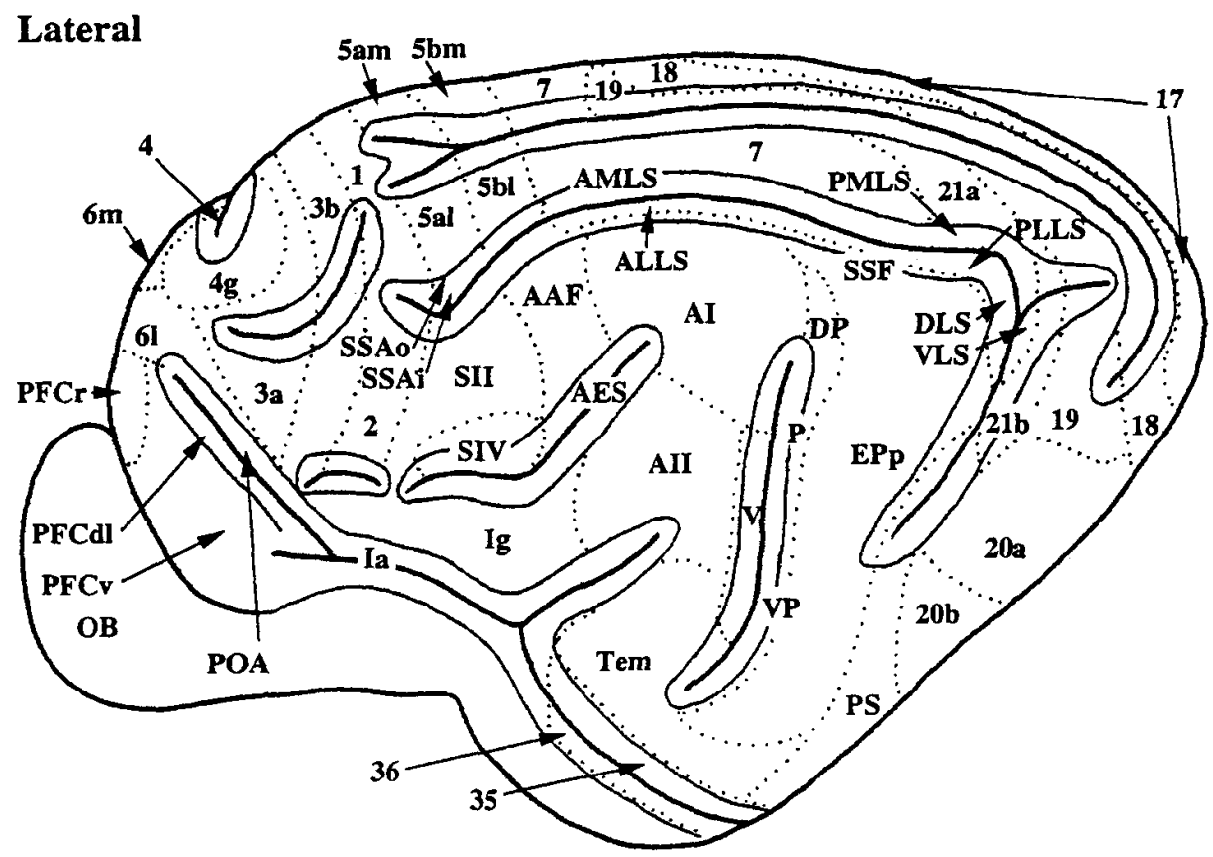

nectional data. The model and the real configurations were then compared using Procrustes rotation.

We report the results of these analyses for subsets of cortical arcas. For this purpose, the areas were divided into the visual system $(17,18$, 19, PMLS, PLLS, AMLS, ALLS, VLS, DLS, 21a, 21b, 20a, 20b, ALG, 7, AES, SVA, PS, EPp, POA, CGa, CGp, 35, 36, ER, Hipp, Amyg), the auditory system (AI, AAF, P, VP, AII, DP, V, SSF, EPp, Tem; CGa, CGp, RS, 35, 36, ER, Hipp. Amyg), the somatomotor system ( $3 \mathrm{a}, 3 \mathrm{~h}$, 1, 2, SII, SIV, 4g, 4, 61, 6m, 5am, 5al, 5bm, 5bl, 5m, SSAi, SSAo, LA, CGa, CGp, Ia, Ig, 35, 36, ER, Hipp, Amyg), the frontolimbic complex (61, 6m, PFCr, PFCdm, PFCdl, PFCv, IA, IG, CGa, CGp, LA, RS, PL, IL, 35, 36, PSb, Sb, ER, Hipp, Amyg), and the neocortical sensory systems (17, 18, 19, PMLS, PLLS, AMLS, ALLS, VLS, DLS, 21a, $21 \mathrm{~b}, 20 \mathrm{a}, 20 \mathrm{~b}$, ALG, 7, AES, SVA, PS, AI, AAF, P, VP, AII, DP, V, SSF, EPp, Tem, 3a, 3b, 1, 2, SII, SIV, 4g, 4, 6l, 6m, POA, 5am, 5al, $5 \mathrm{bm}, 5 \mathrm{bl}, 5 \mathrm{~m}, \mathrm{SSAi}, \mathrm{SSAo}$ ).

\section{Results}

\section{Cortical parcellation}

Our parcellation map is shown in Figure 1, and details of the areas, such as their physiological characteristics and references to alternative parcellations, are given in the Appendix. This parcellation of the cortex subsumed 65 areas and included divisions of the prefrontal cortex, limbic structures, and the visual, auditory, and somatosensory-motor cortex.

\section{Cortical connections}

Our survey of the neuroanatomical literature indicated 1139 reported corticocortical connections. The full connectional database, including data on connection density, laminar origin and 


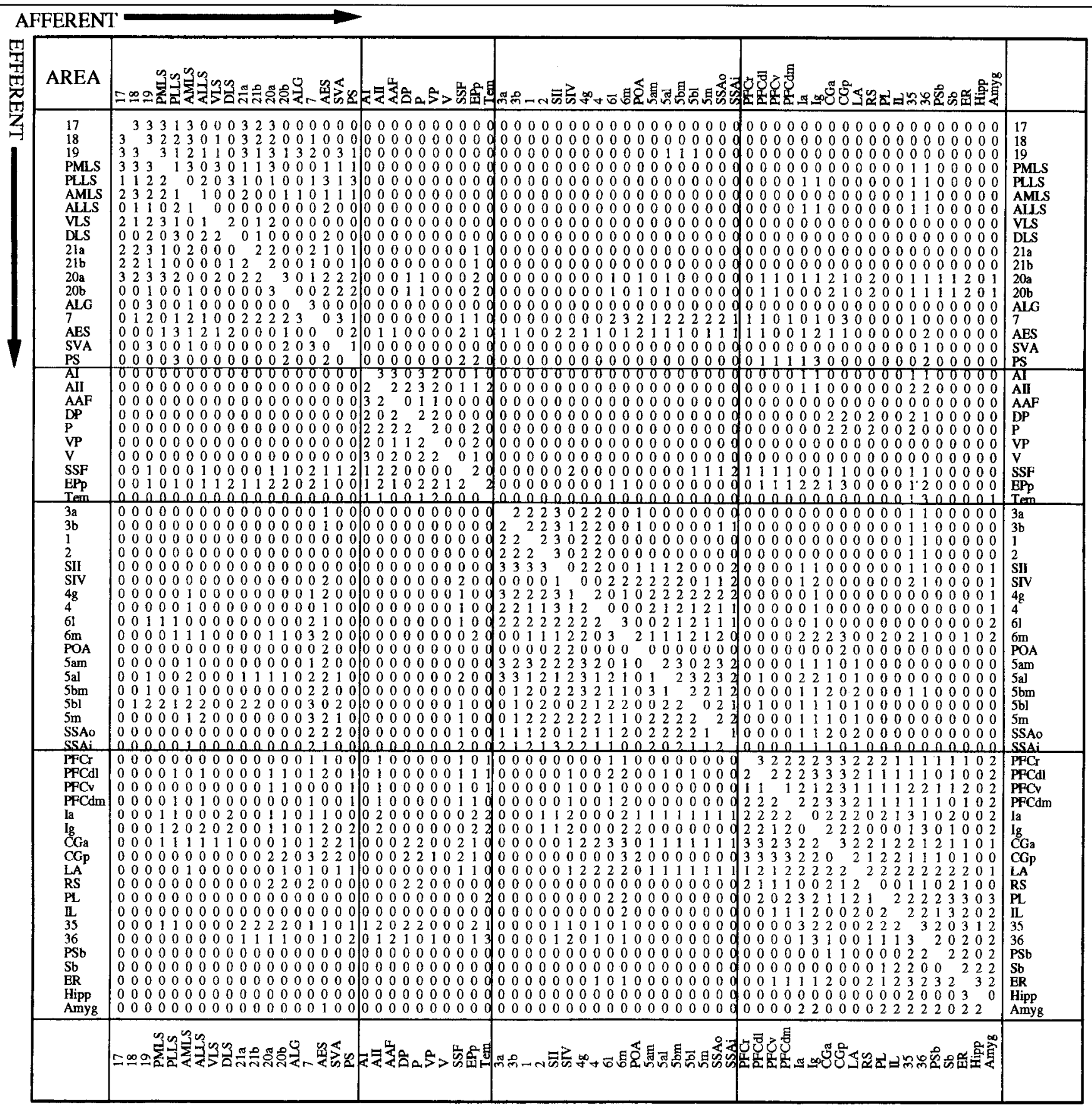

Connections weighted 3 are strong, dense connections, those weighted 2 are intermediate, connections weighted 1 are weak or sparse, and connections weighted 0 have been explicitly reported as absent or are unreported. No information ahout the spatial position of the areas in the brain, the laminar patterns or the continuity or patchiness of connections is represented in the matrix. The connections listed along the horizontal axis are afferent, and those along the vertical axis are efferent.

termination patterns, and references to the appropriate anatomical studies is available by anonymous FTP (ftp crick. physiology.oxford.ac.uk; user name $=$ anonymous; password $=$ your email address; directory $=$ pub; filename $=$ cat_conn.txt).

Table 1 shows the matrix, derived from our connectional database, which formed the basis of the input into the NMDS analyses.

\section{Visual hierarchy}

We used the laminar origin and termination data yielded by our literature survey to classify connections as ascending, descend- ing, or lateral, and then used these directional constraints to arrange the areas in a hierarchy (see Fig. 2). There were sufficient data available to include 22 areas, 17 of which are classically visual and 5 of which are limbic structures: CGa, CGp, areas 35, 36, and ER. The analysis suggests (see Fig. 2) that the visual areas occupy approximately 11 hierarchical levels, with 17 and 18 at the lowest levels, and 20b, AES, and 7 at the highest levels. Above the highest distinctively visual areas are $\mathrm{CGa}, 36,35$, and ER.

The areas included in the hierarchical analysis were linked by 


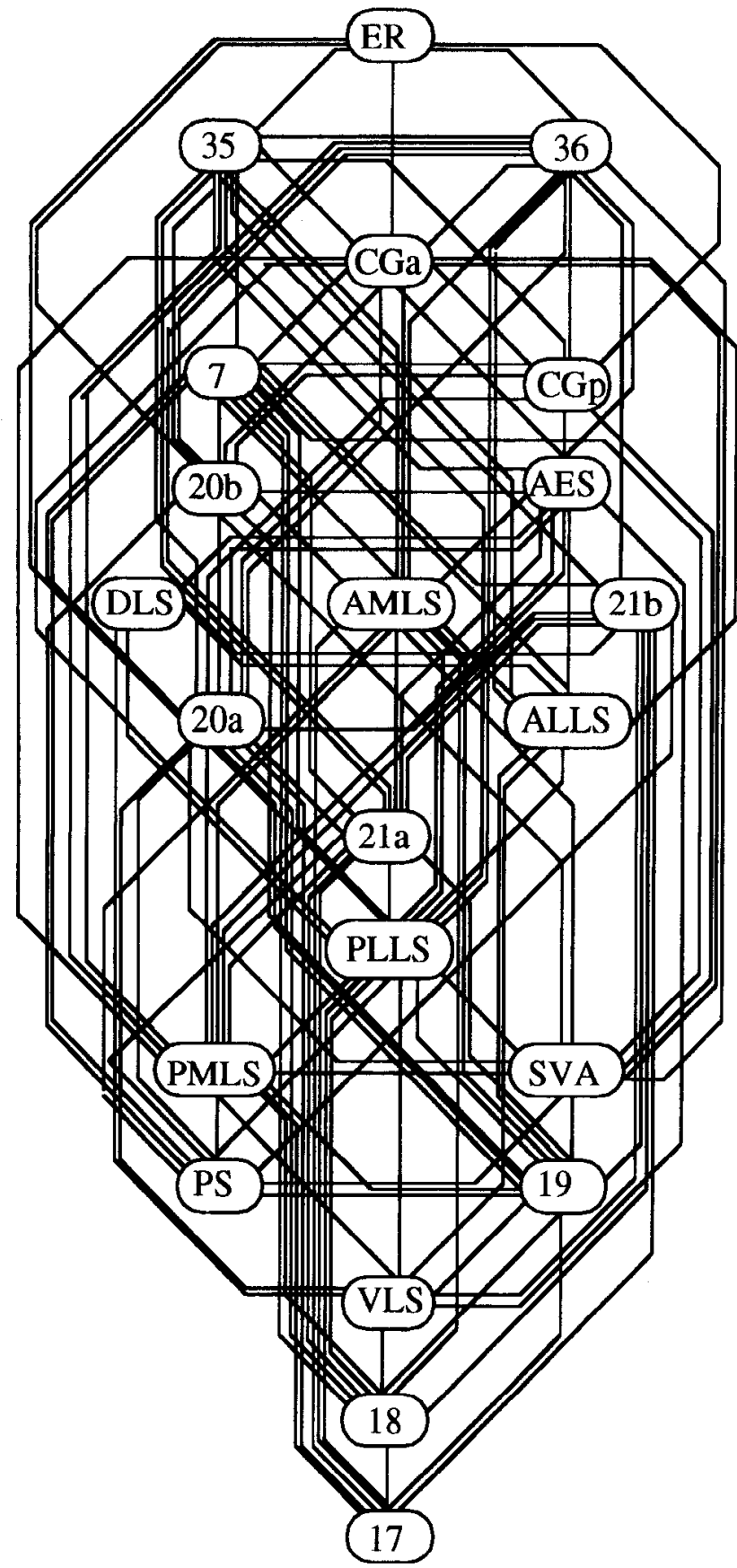

Figure 2. Hierarchical structure of cat visual system. The criteria of Felleman and Van Essen (1991) were applied to the laminar origin and termination data yielded by our literature survey. Connections were classified as ascending, descending, or lateral, and these classifications were used to order the areas in a unidimensional hierarchy. 'The figure shows 224 connections, of which 168 are reciprocal, between 22 cortical areas occupying 14 levels. Forty-two connections could be classified as descending, 20 connections as ascending, and 1 connection as lateral. A further 21 connections were possibly descending, 42 possibly ascending, and 6 possibly lateral. The remaining 91 connections could not be classified or had no data on origin or termination patterns. Fifteen of the classified connections could not be fitted by ordering the areas in a unidimensional hierarchy.
224 connections, of which 168 were reciprocal. Forty-two connections could be classified as descending, 20 connections as ascending, and 1 connection as lateral. A further 21 connections were possibly descending, 42 possibly ascending, and 6 pussibly lateral. The remaining 91 connections could not be classified or had no data on origin or termination patterns. Fifteen of the classified connections could not be fitted by ordering the areas in a unidimensional hierarchy. Much of the laminar origin and termination data is ambiguous, partial, or, in some cases, not classified by the Felleman and Van Essen (1991) criteria. The structure is, therefore, based on only about 63 connections that have reasonably clear and unambiguous laminar patterns.

In 15 connections, however, the origin and termination patterns are not consistent with the hierarchical arrangement. For example, reciprocal projections that are ascending in both directions according to the Felleman and Van Essen (1991) rules seem to exist between 17 and 18, 17 and PLLS, and 20a and PLLS. Reciprocal descending projections occur between PLLS and PMLS, and PMLS and 21a. AMLS appears to receive a lateral projection from PMLS. Area 20a receives ascending projections from $\mathrm{AES}$.

\section{Comparison of visual hierarchy with topology}

The hierarchy derived from our connectional database and a hierarchy of the cat visual system from Felleman and Van Essen (1991) were compared with their corresponding topological structures using Procrustes rotation.

The hierarchical model presented in Figure 2 accounted for $29 \%$ of the variability of, and was statistically significantly related to, the corresponding topological structure $\left(r^{2}=0.29, p<\right.$ 0.0016 ). Figure 3 shows the correspondence between the positions taken by areas in the topological and hierarchical structures when rotated by Procrustes into their best correspondence. Several areas show a high degree of disparity between the two analyses: PS and SVA are hierarchically lower, while AMLS is hierarchically higher than their topological positions suggest.

The hierarchy of Felleman and Van Essen (1991) accounted for $1 \%$ of the variance of its corresponding topological structure, and the relation between the two models was not significant.

\section{Auditory hierarchy}

A hierarchical model of the cat auditory system has been described by Rouiller et al. (1991). We used Procrustes rotation to compare this hierarchy with the corresponding topological structure (Fig. 4). In Figure 4, the topological and hierarchical positions of each area are shown linked, and it can be seen that the two analyses place the areas in a very similar order. Quantitatively, the hierarchical model accounted for $41 \%$ of the variability of the topological model $\left(r^{2}=0.41\right)$, and the two structures were significantly related $(p<0.0016)$.

\section{Other cortical systems}

We found insufficient data on the laminar origin and termination patterns to attempt hierarchical analysis of the relation between somatosensory-motor areas.

Where data were available for connections between frontolimbic areas, it was apparent that the laminar origins and terminations did not generally conform to the criteria for ascending, descending, or lateral patterns. Therefore, we could not apply the rules of hierarchical analysis to the network of connections between these structures. 


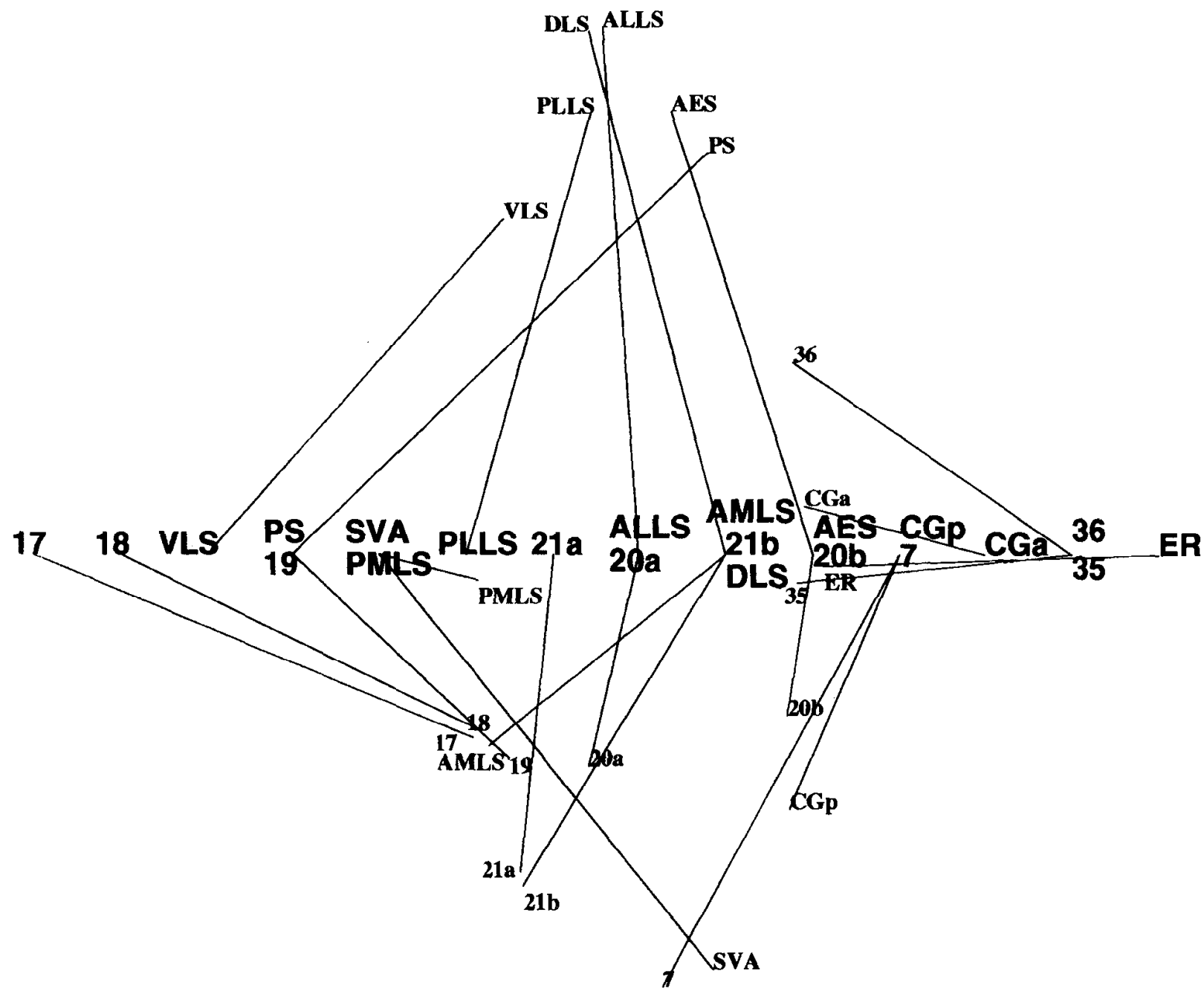

Figure 3. The comparison between the topological and hierarchical structures of the cat visual system. The central horizontal "line" of cortical areas (in large type) shows the hierarchical organization of the cat visual system (Fig. 2). The topology (in small type) was computed from the connection data in Table 1 . The hierarchy includes 224 connections, between 22 cortical areas that occupy 10 levels. Lines are drawn, linking the topological and hierarchical positions of each area. The lines that cross a large number of other lines link areas with a large divergence between their topological and hierarchical positions. The hierarchical model accounts for $29 \%$ of the variability of the topological model $\left(r^{2}=0.29\right)$, and the two structures are significantly related $(p<0.0016)$

\section{Comparisons between simple connection models and experimentally demonstrated connections}

Visual system. The nearest-neighbor matrix accounted for $26.1 \%$ of the real connections found between the visual areas of the cat (Fig. 5, Table 2). Nearest-neighbor connectivity would evidently produce too few connections to give a good account of real cortical connectivity. However, 79.3\% of the connections that are predicted by the nearest-neighbor connection rule have been demonstrated in anatomical studies (Fig. 6, Table 2).

Predicted connections between nearest-neighbors that have not been demonstrated experimentally include connections between area 17 and SVA, 17 and CGp, afferent connections to SVA from the cingulate cortex, projections from VLS to 21 a and $21 \mathrm{~b}$, a projection from $21 \mathrm{a}$ to VLS, and a projection from $20 \mathrm{~b}$ to ER. The absence of reports of connections that are predicted by neighborhood wiring models may be due to incomplete collation of data, incomplete neuroanatomical studies, or genuine absence of the projection. As $79.3 \%$ of nearest-neighbor connections have been found experimentally, true absence of con- nections between neighboring areas may show a discontinuity in the general pattern of cortical connections. One group of missing connections and, therefore a possible discontinuity, exists between the early sensory areas $(17,18$, and primary somatosensory cortex), and the dorsal limbic structures (CGA, CGp, RS, and LA). This is considered in more detail later.

The nearest-neighbor-or-next-door-but-one matrix accounted for $56.6 \%$ of the connections so far reported between areas of the cat visual system (Fig. 7, Table 2), and $61.1 \%$ of the connections predicted by the model have been demonstrated in anatomical studies (Fig. 8, Table 2).

Anatomical connections not predicted by nearest-neighbor-ornext-door-but-one connectivity include connections of 17 and 18 with the lateral suprasylvian areas, most of the visual connections of AES, the connections between 17 and 21a, 21b, and $20 \mathrm{a}$, and projections from areas 35 and 36 to the lateral suprasylvian visual areas. Therefore, there are certain long-range connections, over and above those connections accounted for by local connections, linking areas in the visual system, particularly 

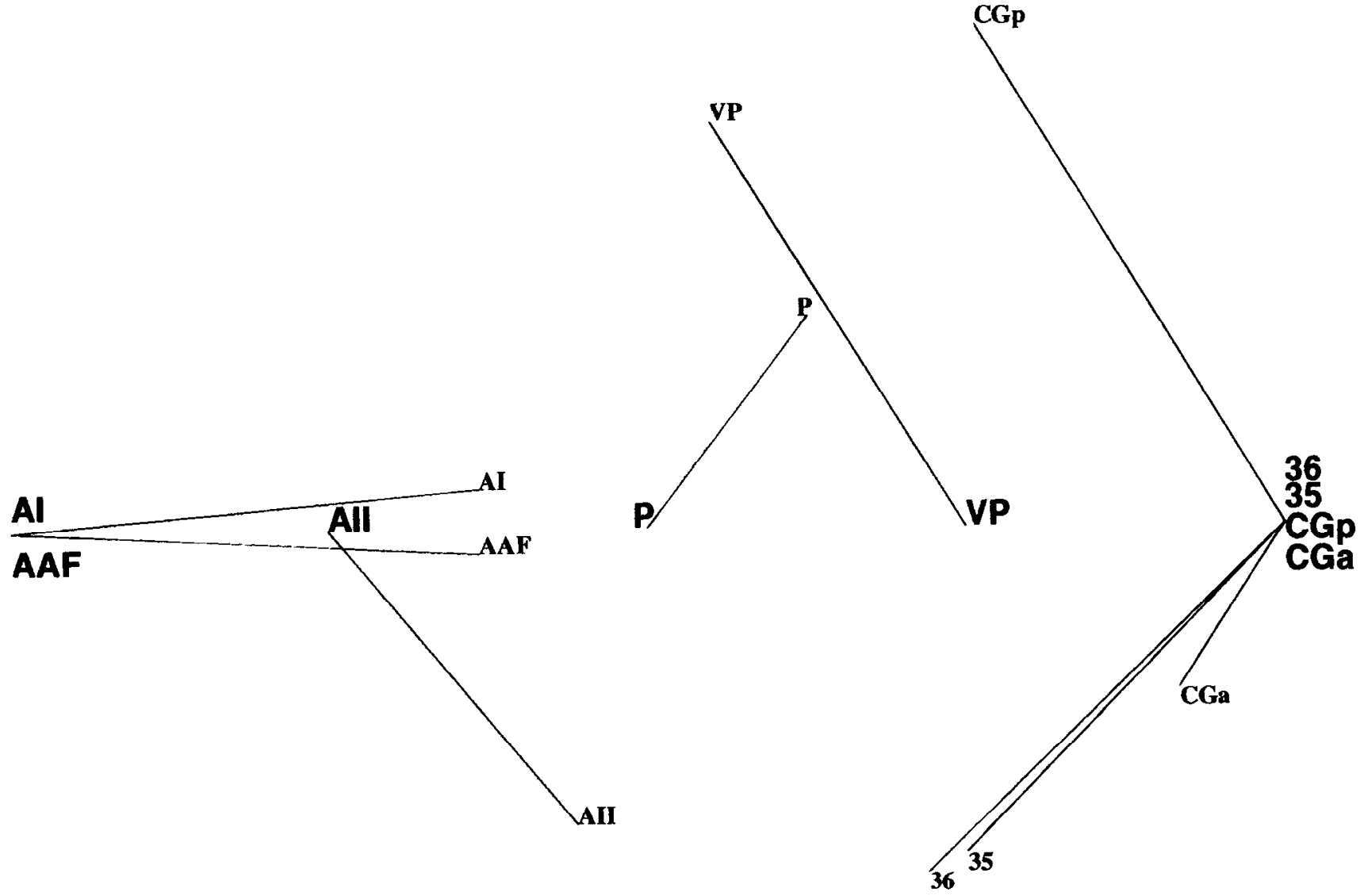

Figure 4. The comparison between the topological and hierarchical structures of the cat auditory system. The central horizontal "line" of cortical areas (in large type) shows the hierarchical organization of the cat auditory system and was taken from Rouiller et al. (1991). The topology (in small type) was computed from the connection data in Table 1 . The hierarchy includes 44 connections, between 9 cortical areas that occupy 5 levels. Lines are drawn, linking the topological and hierarchical positions of each area. The lines that cross a large number of other lines link areas with a large divergence between their topological and hierarchical positions. The hierarchical model accounts for $41 \%$ of the variability of the topological model $\left(r^{2}=0.41\right)$, and the two structures are significantly related $(p<0.0016)$.

17 and 18 with the lateral suprasylvian areas, and the lateral suprasylvian areas with AES.

Connections that are predicted by nearest-neighbor-or-nextdoor-but-one connectivity, but which have not, so far, been demonstrated in anatomical studies include connections between 17 , 18 , and 19 and elements of the frontolimbic complex, between the cingulate cortex and the parahippocampal regions, and a number of afferent projections to SVA and PS.

Auditory system. The nearest-neighbor matrix accounts for $27.9 \%$ of the connections of the auditory system (Fig. 5, Table 2 ), and $70.6 \%$ of the connections predicted by the model have been found in anatomical studies. Connections that are predicted by nearest-neighbor connectivity, but which have not been reported, include connections from DP and SSF to AI, projections from AII, P, and VP to field V, projections from AI, AAF, and $\mathrm{DP}$ to SSF, and projections from Tem to the insular cortex, EPp, and $\mathrm{V}$ (Fig. 6, Table 2).

The nearest-neighbor-or-next-door-but-one model accounts for $61.6 \%$ of the connections (Fig. 7, Table 2) so far described in the auditory cortex. Of the connections predicted by the model, 64.6\% have been reported (Fig. 8, Table 2). Anatomical connections not accounted for by nearest-neighbor-or-next-door-but-one connectivity include those from AI and AII to 35 and 36; those from DP and $\mathrm{P}$ to cingulate cortex, retrosplenial cortex, and area 35; projections to AAF from VP and V; and the connections be- tween CGa and CGp, and SSF EPp (Fig. 7, Table 2). Figure 8 shows that many connections predicted by nearest-neighbor-ornext-door-but-one connectivity have not been reported in the anatomical literature. For example, DP, V, SSF, Tem, Ia, and Ig lack a number of nearest-neighbor-or-next-door-but-one connections.

Somatosensory-motor system. Nearest-neighbor connectivity accounted for $18.2 \%$ of the connections so far described in the somatosensory-motor system (Fig. 5, Table 2) and $75.6 \%$ of the connections predicted by the model have been demonstrated in anatomical studies (Fig. 6, Table 2). Connections predicted by the model that have not been described include projections from $5 \mathrm{al}, 5 \mathrm{am}, 5 \mathrm{~m}, \mathrm{SSAo}$, and SSAi to divisions of the primary somatosensory cortex, and connections between the anterior cingulate cortex and 3a and 3b (Fig. 6).

Nearest-neighbor-or-next-door-but-one connectivity accounted for $44.4 \%$ of the anatomical connections reported in the somatosensory-motor system (Fig. 7, Table 2) -a lower figure than for the other sensory systems. Of the connections predicted by the model, $65.9 \%$ correspond to anatomically identified connections (Fig. 8, Table 2). Figure 7 shows that nearest-neighbor-ornext-door-but-one connectivity failed to account for a large number of connections between $4,4 \mathrm{~g}, 61$ and $6 \mathrm{~m}$, and area 5 (which span 3a, 3b, 1 and 2); projections from areas 35 and 36 to the primary somatosensory areas; and projections from the amygdala to SII, SIV, $4 \mathrm{~g}, 4$, and 61 . 


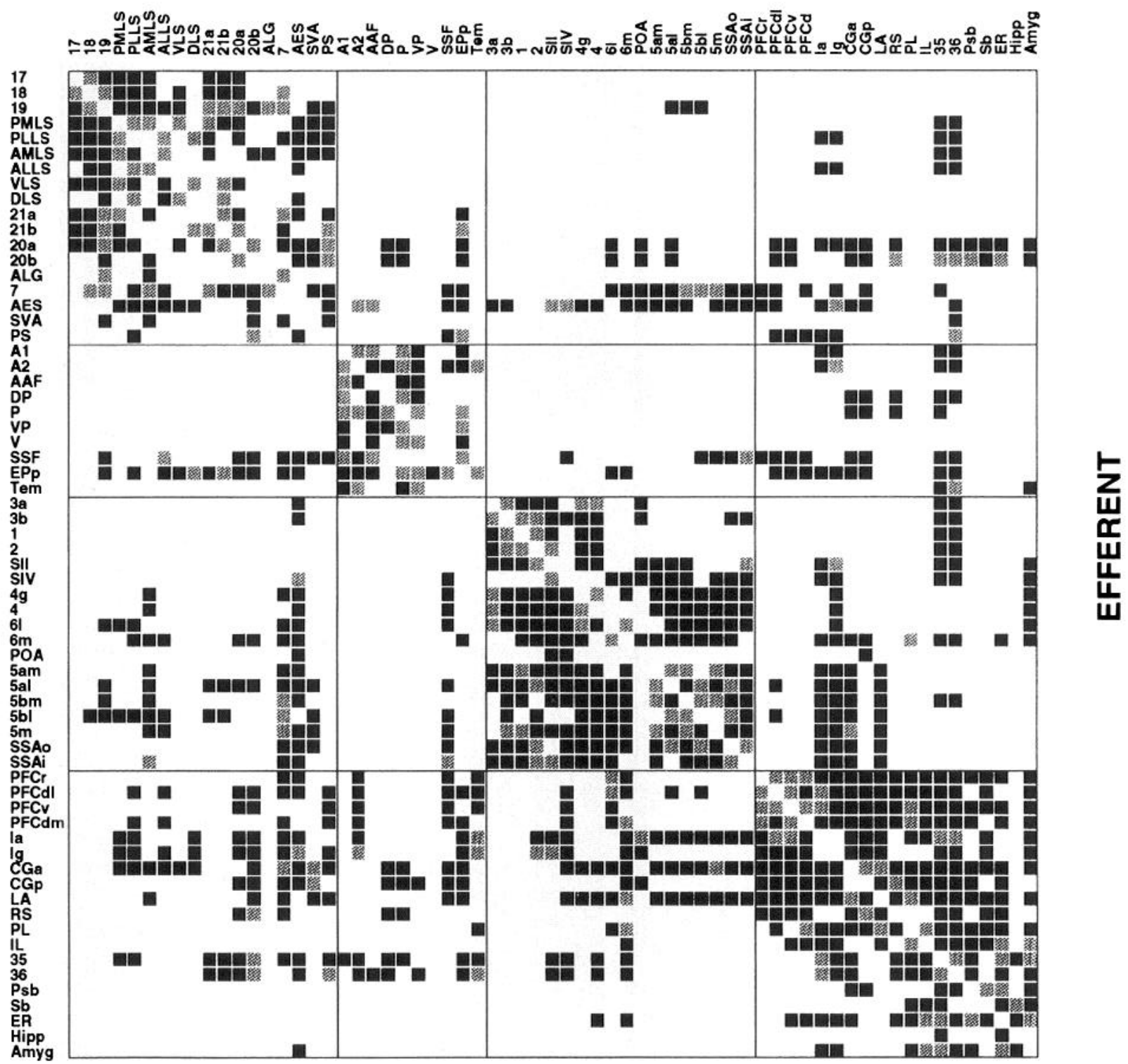

\section{AFFERENT}

Figure 5. Corticocortical connections compared with the "nearest-neighbor" model. All squares represent real connections (Table 1). Gray squares represent real connections that are accounted for by the "nearest-neighbor" model, while black squares represent real connections that are not accounted for by the model. The figure shows 1139 connections, of which $20.1 \%$ are predicted by "nearest-neighbor" wiring.

Connections predicted by nearest-neighbor-or-next-door-butone that have not been demonstrated in tracing studies, include a large number of connections between the primary somatosensory cortex and limbic areas, and efferent projections from several divisions of area 5,61 , and $6 \mathrm{~m}$, to the primary somatosensory areas. The lack of reports on the existence of these connections may reflect connectional discontinuities at the borders of functionally dissimilar groups of cortical areas.

Frontolimbic structures. Nearest-neighbor connectivity accounted for $20.2 \%$ of the anatomical connections (Fig. 5, Table 2 ), and $81.8 \%$ of the connections predicted by the model have been found experimentally (Fig. 6, Table 2). Connections predicted by nearest-neighbor connectivity that have not been demonstrated anatomically include projections from the rostral and dorsolateral divisions of the prefrontal cortex to area 61 ; con- nections between the granular and agranular insular; and projections from PSb to RS and Sb (Fig. 6).

Nearest-neighbor-or-next-door-but-one connectivity accounted for $50.2 \%$ of the known connections of the frontolimbic system (Fig. 7, Table 2), and $77.9 \%$ of the connections predicted by the model have been found in anatomical studies (Fig. 8, Table 2). From Figure 7 it is apparent that the connections of the amygdala, CGa, CGp, 35, 36, ER, PSb, and Sb are more widespread than predicted by nearest-neighbor-or-next-door-but-one connectivity. Relatively few connections predicted by nearest-neighbor-or-nextdoor-but-one connectivity have not been reported (Fig. 8). They include, however, efferent projections from the prefrontal cortex to $6 \mathrm{l}$ and $6 \mathrm{~m}$; and a number of missing projections to 61 .

Global cortical system. The nearest-neighbor model accounted for $20.1 \%$ of all the connections so far demonstrated between 
Table 2. Quantitative comparisons between border relation models and connectional topology

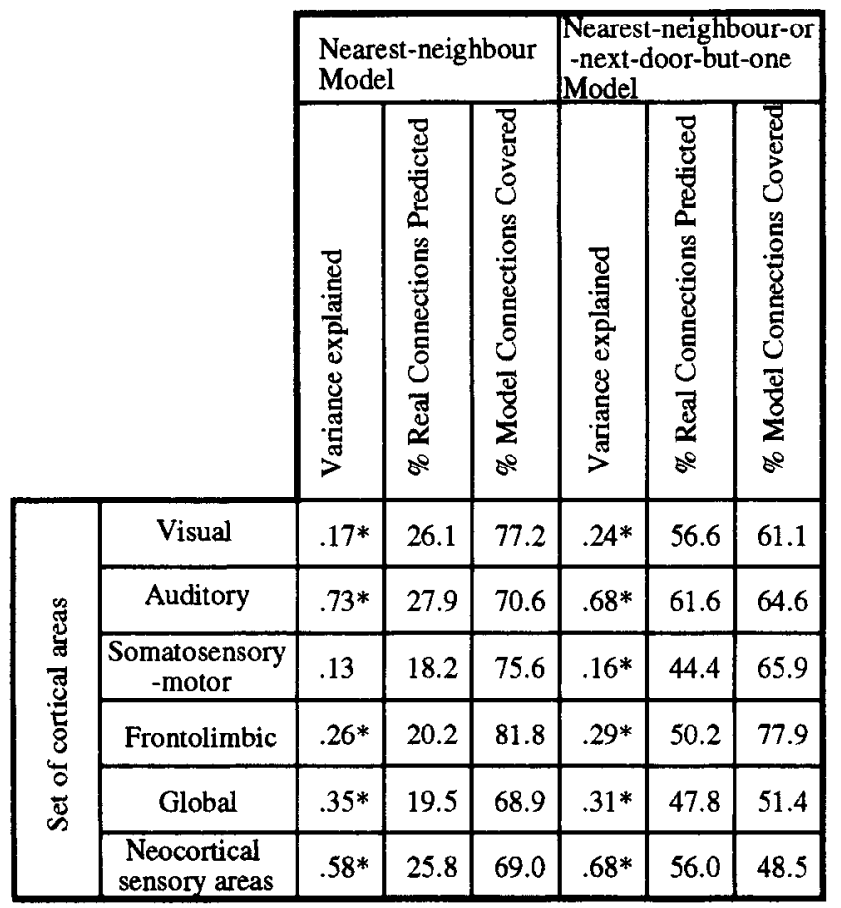

The table summarizes the results of the quantitative comparisons made between the topology of the visual, auditory, somatosensory-motor, and frontolimbic systems, and the entire cortex (global), with the border relation models. The "Neocortical sensory areas" include all cortical areas except those in the frontolimbic system $(61,6 \mathrm{~m}, \mathrm{PFCr}$, PFCdl, PFCdm, PFCv, LA, RS, PL, IL, 35, 36, ER, CGa, CGp, Sb, PSb, Hipp, and Amyg). "\% Real Connections Predicted" shows the percentage of anatomically demonstrated connections that are predicted by the border relation model. The "\% Model Connections Covered" shows the percentage of the models' connections that overlap with real connections.

* Comparisons that are statistically significant $(p<0.0016)$ by Procrustes rotation in $2 \mathrm{D}$.

the 65 cortical areas of the cat (Fig. 5, Table 2), and $70.1 \%$ of all connections between nearest neighbors have been documented (Fig. 6, Table 2). Nearest-neighbor connections that have not been demonstrated include connections between the anterior suprasylvian visual areas (ALLS and AMLS), and SSAi and SSAo; projections from $5 \mathrm{~m}, \mathrm{SSAi}$, and SSAo to the primary motor areas; and some projections from the prefrontal cortex to 61, 6m, and POA (Fig. 6).

The nearest-neighbor-or-next-door-but-one model accounted for $47.8 \%$ of the known corticocortical connections (Fig. 7, Table 2 ), and $51 \%$ of all connections predicted by this model have been found experimentally (Fig. 8, Table 2).

Figure 7 highlights fascicles of connections not predicted by nearest-neighbor-or-next-door-but-one connectivity. Both the afferent and efferent connections of AES with the visual areas, motor, and premotor areas, area 5, POA, and frontolimbic structures are unusual from the perspective of neighborhood connectivity. The connections of the divisions of area 5 with SII, SIV, motor, and premotor areas are also poorly accounted for by the local connection rules, suggesting the presence of one or more fascicle. Connections, particularly efferent ones, of areas 35 and 36 are more widespread than would be predicted from the simple rules, as are the connections of the amygdala, particularly those outside the frontolimbic complex. Connections of $6 \mathrm{~m}$ with the early visual areas also suggest the presence of a fascicle, which may be related to the eye field contained within $6 \mathrm{~m}$ (Guitton et al., 1978).

Figure 8 shows, in black, the connections predicted by the nearest-neighbor-or-next-door-but-one model that have not been demonstrated experimentally. These missing connections may be a guide to regions of cortex that remain more connectionally isolated than would be expected. For example, there is a major group of absent connections to the visual areas of the lateral suprasylvian sulcus (PMLS, PLLS, AMLS, ALLS, DLS,VLS) from the auditory areas, SSF, and EPp. The areas of the dorsal limbic cortex (CGa, GCp, LA, and RS) are less connected with the early visual, and primary somatosensory areas than local connection rules would suggest.

\section{Comparison between simple connection rules and experimentally demonstrated connectional topology}

Visual system. We used Procrustes rotation to make quantitative comparisons between the topological map of the visual system and maps derived from nearest-neighbor and nearest-neighboror-next-door-but-one connections. The topological structure derived by NMDS from the nearest-neighbor connectivity matrix explained $17 \%$ of the variance of the topological structure derived from the experimental connectional data. This value, although low, was statistically significant (see Table 2). The topological structure derived from nearest-neighbor-or-nextdoor-but-one connectivity accounted for $24 \%$ of the variance of the topology of the visual system, and, again, this value was statistically significant. Although significantly related to the pattern of connectivity, simple neighborhood connectivity is a poor predictor of the pattern of connections within the visual system.

Auditory system. In contrast to the visual system, the topology of the auditory system was very well accounted for by the neighborhood wiring models. The nearest-neighbor connection rule explains $73 \%$, and the nearest-neighbor-or-next-door-but-one model $68 \%$, of the variance of the topological structure derived from the real connectivity data (Tablc 2, Fig. 9).

Somatosensory-motor system. The nearest-neighbor and nearest-neighbor-or-next-door-but-one models explain, respectively, $13 \%$ and $16 \%$ of the variance of the topological structure derived from the connection data. Only the second of these values, for the nearest-neighbor-or-next-door-but-one, is statistically significant (Table 2). The bad fit between the model and the real connectivity arises, in part, because the topologically lowest areas (3a, 3b, 1, and 2) form an island of cortex separating the motor and premotor cortex from their topological neighbors: area 5, SII, and SIV. The large number of connections that span the primary somatosensory cortex, linking the higher somatosensory areas with the motor and premotor areas, are not accounted for by the neighborhood wiring models.

Frontolimbic system. The topological structures derived from the analyses of the nearest-neighbor and nearest-neighbor-ornext-door-but-one models predicted, respectively, $26 \%$ and $29 \%$ of the variance of the solution derived from the connection data, and both comparisons were statistically significant (Table 2).

Global cortical system. The nearest-neighbor and nearestneighbor-or-next-door-but-one models explained, respectively, $35 \%$ and $31 \%$ of the variance in the topological structure derived from the global connection matrix. Both these values were statistically significant (Table 2).

Neocortical sensory systems. Comparisons of the neighborhood wiring matrices with the real connectional matrices (Figs. 5-8) showed that the simple neighborhood wiring models were 


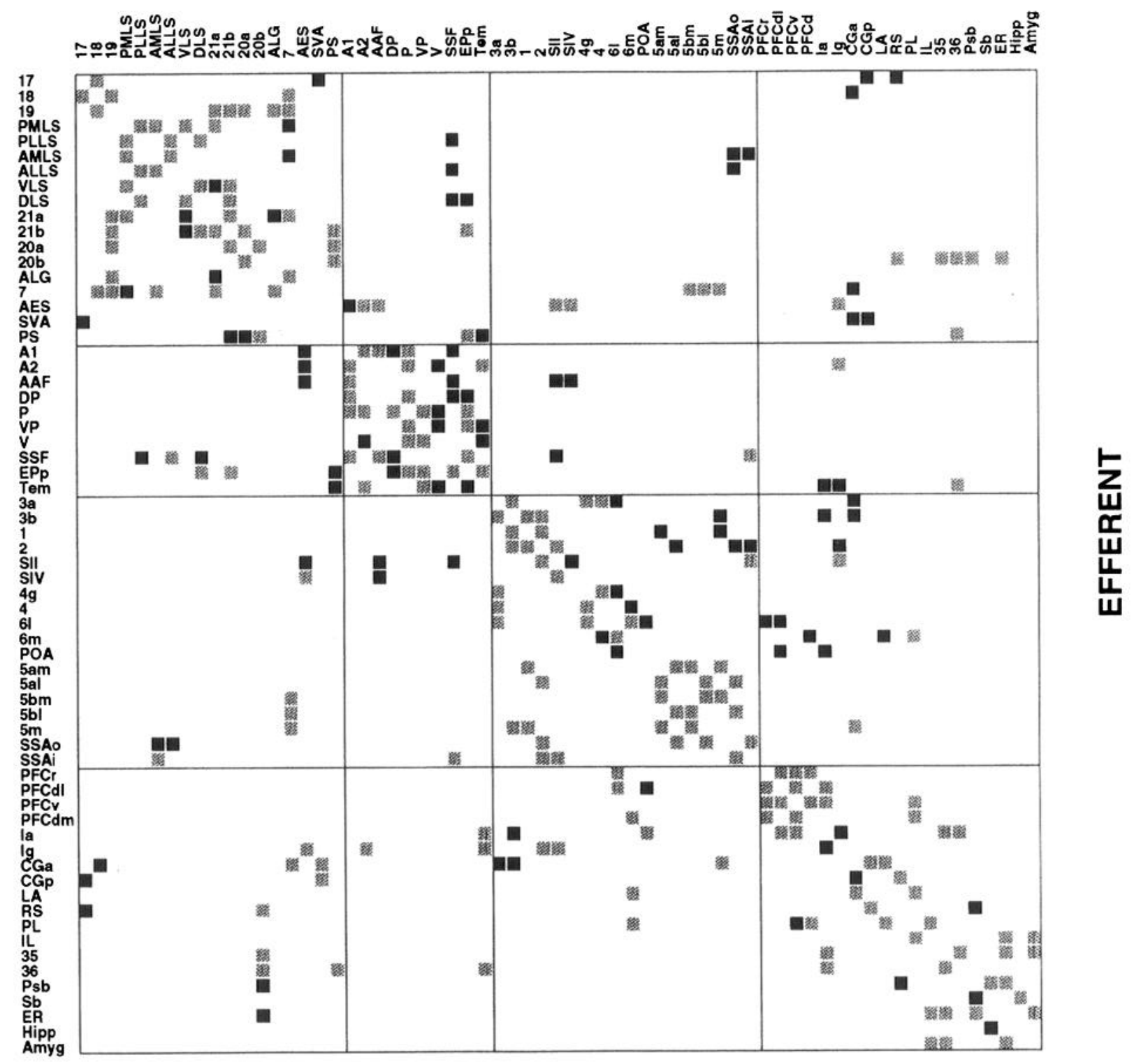

\section{AFFERENT}

Figure 6. "Nearest-neighbor" model compared with corticocortical connections. Gray squares represent the connections predicted by the model that have corresponding anatomically identified connections. Black squares represent model predictions that have not been demonstrated experimentally. The figure shows 328 "nearest-neighbor" connections, of which $69.8 \%$ overlap with real connections.

particularly poor in accounting for the connectivity of the lower sensory areas with the dorsal limbic structures such as the cingulate, retrosplenial, and anterior limbic cortex. Consequently, a better agreement would be expected between the topological solutions of the real and model connectivity matrices if the border between the neocortical sensory-motor systems and the frontolimbic complex were excluded. We examined this idea by excluding the frontolimbic complex from the analyses, including only 46 neocortical areas of the visual, auditory, and somatosensory systems.

The nearest-neighbor and nearest-neighbor-or-next-door-butone models now explain $58 \%$ and $68 \%$ of the topology derived from the anatomical connections of these neocortical areas (Fig. 10, Table 2). The models predict the gross division of the cortex into three clusters, corresponding to the visual, somatosensory- motor, and auditory systems, but are less successful at specifying the position of areas within each cluster. In the solution from nearest-neighbor-or-next-door-but-one connectivity, the clusters are less tight than in the solution of the real data, and the positions of several areas are markedly wrong. Nearest-neighboror-next-door-but-one connectivity, for example, places AES, SII, and SIV, between the somatosensory and auditory systems (Fig. 10).

The fit of the neighborhood wiring models of the "neocortical" group of areas with their corresponding connectional topology is better than the fit between the neighborhood wiring models and the global topology. We think that this may be due to different connection rules applying across the border between the neocortical sensory areas and the neighboring limbic cortex, particularly the dorsal limbic areas. 


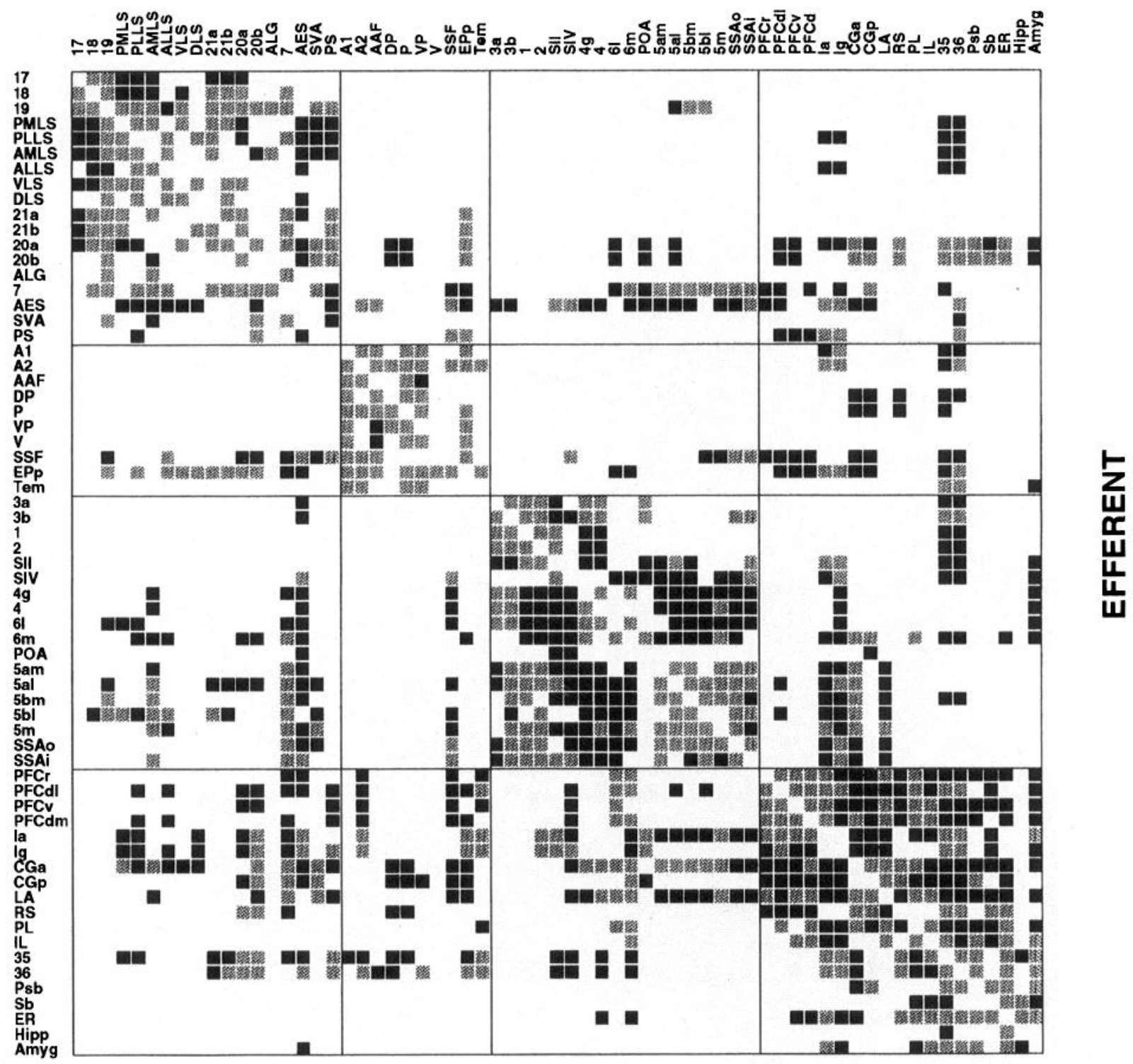

\section{AFFERENT}

Figure 7. Corticocortical connections compared with the "nearest-neighbor-or-next-door-but-one" model. All squares represent real connections (Table 1). Gray squares represent real connections that are accounted for by the "nearest-neighbor-or-next-door-but-one" model, while black squares represent real connections that are not accounted for by the model. The figure shows 1139 connections, of which $47.8 \%$ are predicted by "nearestneighbor-or-next-door-but-one" wiring.

\section{Discussion}

We have quantitatively analyzed neuroanatomical data on cat cortical connectivity. The results show, first, that hierarchies derived by considering laminar origin and termination data are statistically significantly related to the ordering of areas derived by optimization of the pattern of their area-to-area connectivity. This result would not be expected if either independent type of analysis were producing spurious orderings of the areas. The results, therefore, support the view that the central sensory systems that have been analyzed by these means are hierarchically organized, and indicate aspects of the orderings of cortical stations in the hierarchies. Second, the results show quantitatively that the overall pattern of cat corticocortical connectivity is well predicted by simple neighborhood wiring models, with the ex- ception of those areas that are separated by discontinuities in this connectivity pattern or are connected by long-distance fiber fascicles.

\section{Cortical parcellation and identity of cortical areas}

The analyses presented in this article depend upon a valid cortical parcellation scheme, so uncertainties in cortical parcellation present us with a number of problems. First, interareal connections may be misassigned. Second, intrinsic intraareal connections may be mistakenly included as interareal connections (for example, 3 b, 1, and 2 may constitute a single "somatic koniocortical area," see Felleman et al., 1983). Third, errors in the parcellation could produce both under and over estimates of border relation connections. We regard the scheme presented here 


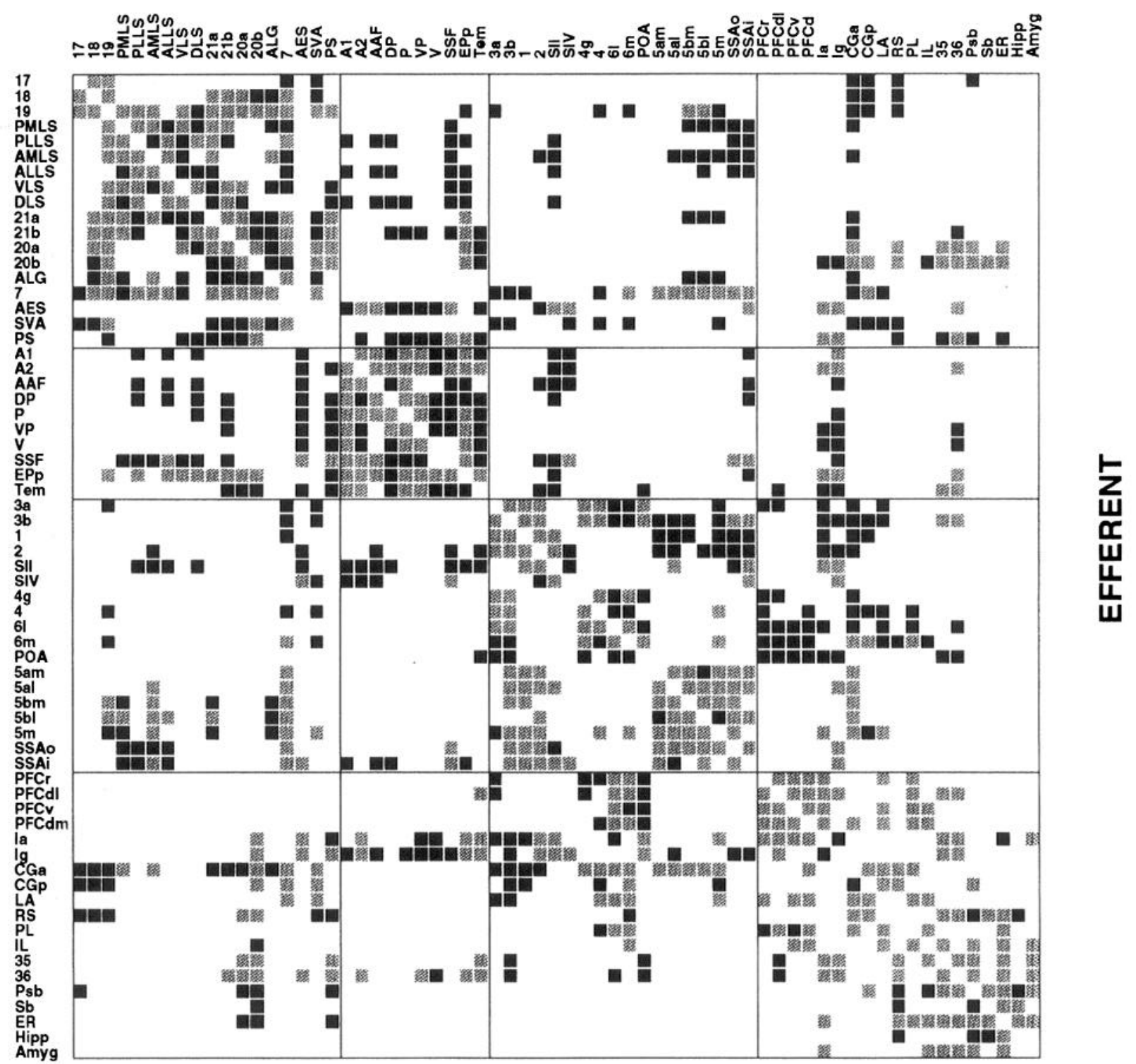

\section{AFFERENT}

Figure 8. "Nearest-neighbor-or-next-door-but-one" model compared with cortical-cortical connections. Gray squares represent the connections predicted by the model that have corresponding anatomically identified connections (Table 1). Black squares represent model predictions that have not been demonstrated experimentally. The figure shows 1068 "nearest-neighbor-or-next-door-but-one" connections, of which $51.0 \%$ overlap with real connections.

as a working model and expect it to evolve as more data becomes available.

\section{Hierarchical and optimization analyses}

Hierarchical analysis, if its assumptions about the importance of input to different cortical layers are correct, is an important source of insight into the likely direction of flow of signals through cortical systems. Nonetheless, having performed it, we have some observations. The first is that hierarchical models are unidimensional. While the relative level of areas in a hierarchical diagram is principled, the position of the areas within a level is not. Put another way, "higher-than" or "lower-than" assignments are based on the application of the rules to the connection data, but none of the rules specifies whether an area should be placed "to-the-left-of" or "to-the-right-of" another area. Because of this, although hierarchical diagrams are often presented in two dimensions, only the vertical dimension is meaningful, while the left-to-right dimension is arbitrary. It follows that features of a system that are not hierarchical, if present, must be underrepresented. In the monkey visual system, for example, the possible segregation of areas into two subsystems, one more concerned with pattern vision and the other more with spatial vision (e.g., Ungerleider and Mishkin, 1982; Young, 1992a), is not illuminated by hierarchical analysis. A hierarchical diagram in which the left to right positions of all the areas were shuffled would be just as consistent with the objective rules. We have made explicit in our hierarchy for the cat visual system that the left-to-right dimension of Figure 2 is not meaningful. 


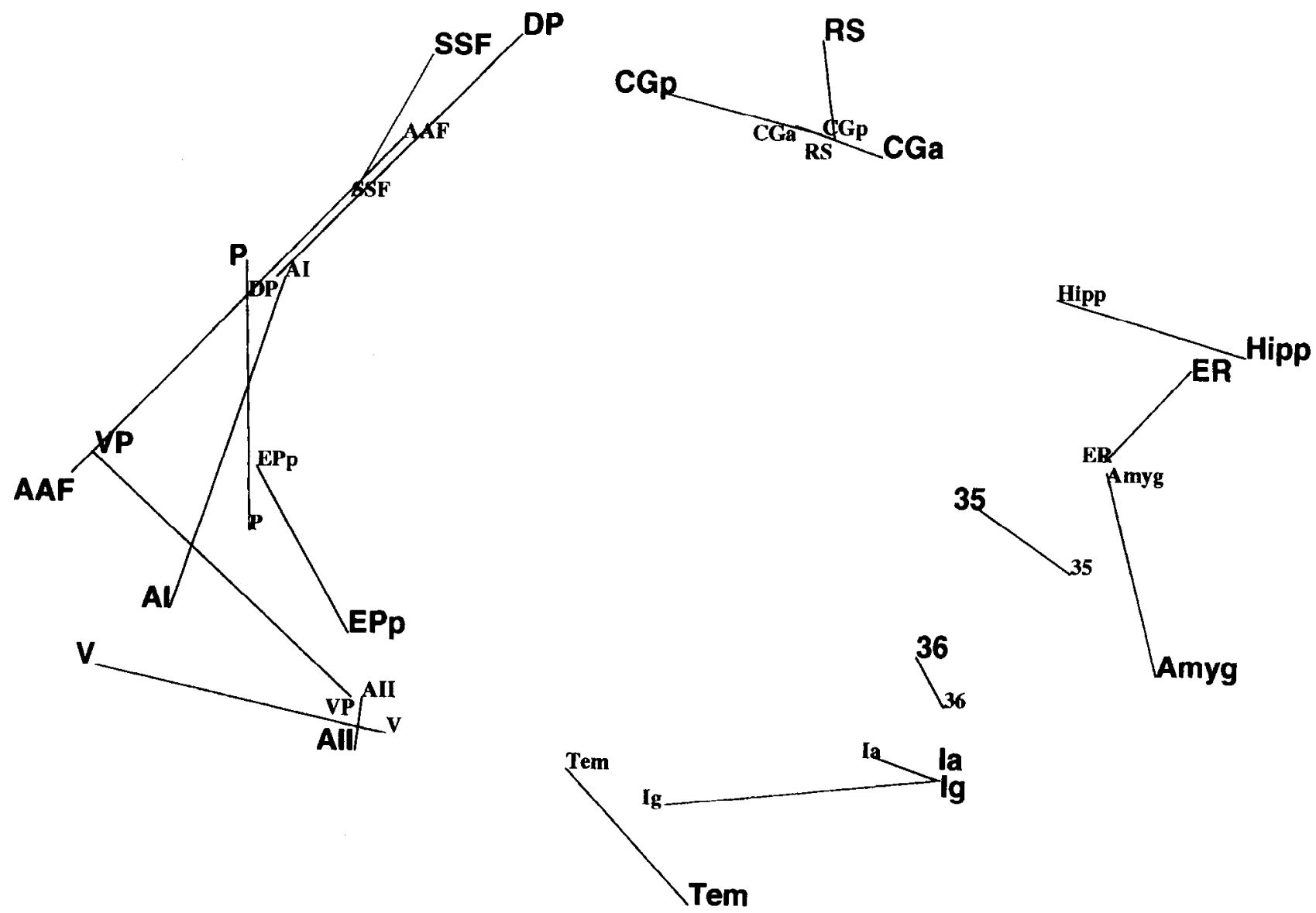

Figure 9. Comparison between the Real and Nearest-neighbor topology of the cat auditory system. The labels in large type show the topological organization of the cortical areas computed from the anatomical connection data in Table 1. The labels in small type show the topological organization of the same areas computed from the connections predicted by "nearest-neighbor" wiring. Procrustes rotation was used to rotate and scale the two structures. Lines are drawn linking the position of each area in the two structures, and illustrate the disparity between the real topology and the topology predicted by "nearest-neighbor" wiring. The model explains $73 \%$ of the variance of the real topology $\left(r^{2}=0.73\right)$, and their relation is significant $(p<0.0016)$.

A second observation is that hierarchical analysis requires detailed anatomical information about the origin and termination patterns of projections before the level of an area in the hierarchy can be inferred. In all species, many more connections have been described than those for which interpretable laminar information is available. For example, of the 305 connections drawn in the hierarchical diagram of the monkey visual system, only about 80 have information on both laminar origin and termination (Felleman and Van Essen, 1991). Our hierarchical analysis of the cat visual system was based on only about 48 connections classifiable on the basis of their laminar arrangement, out of 193 known connections. Consequently, the majority of known connections have no role in determining hierarchical structure in this schemc.

A third observation concerns the fact that laminar patterns in the cat often do not fit the criteria for ascending, descending, and lateral connections. We find that many connections cannot, at present, be unambiguously classified. This ambiguity is to be expected for many of the connections where there are data for the layers only of origin or termination, particularly those connections that have bilaminar origins (which can give rise to connections of any hypothetical direction). A large number of connections, however, for which there are data about both laminar origin and termination, still do not fall into one of the recognized categories. This is particularly the case for connections between limbic structures, such as the prelimbic and infralimbic areas and the perirhinal and entorhinal cortex, but is true even in the visual system. For example, the projection from PLLS to PMLS originates in layers VI and V and terminates in the middle and superficial layers, and the projection from area 18 to area 17 originates predominantly in layers II and III but also from layer $\mathrm{V}$ and terminates in the middle and superficial layers (Symmonds and Rosenquist, 1984a,b. We note similar difficulties with the projections from 17 to 19,19 to PMLS, 20a to PMLS, ALLS to PLLS, 20a to PMLS, PLLS to DLS, 17 to $21 \mathrm{a}, 18$ to 21a, ALLS to 7, DP and P to RS, ER to CGa, CGp, PL and IL, many neocortical projections to 35 and 36 , and connections between parahippocampal structures). It is difficult to see how these connections, and those of subcortical structures, which do not possess a neocortical laminar structure, could be incorporated into a hierarchy. Hierarchical analysis may emphasize classifiable projections and de-emphasize information in unclassifiable connections.

A fourth observation is that there are often inconsistencies and reciprocity mismatches in the data that hinder the hierarchical assignment of areas, even when considering only classifiable connections. For example, PLLS and area 17 have reciprocal connections, both of which appear to be ascending. In the macaque visual system, for which the data on laminar termination patterns is relatively good, at least 33 of the connections 


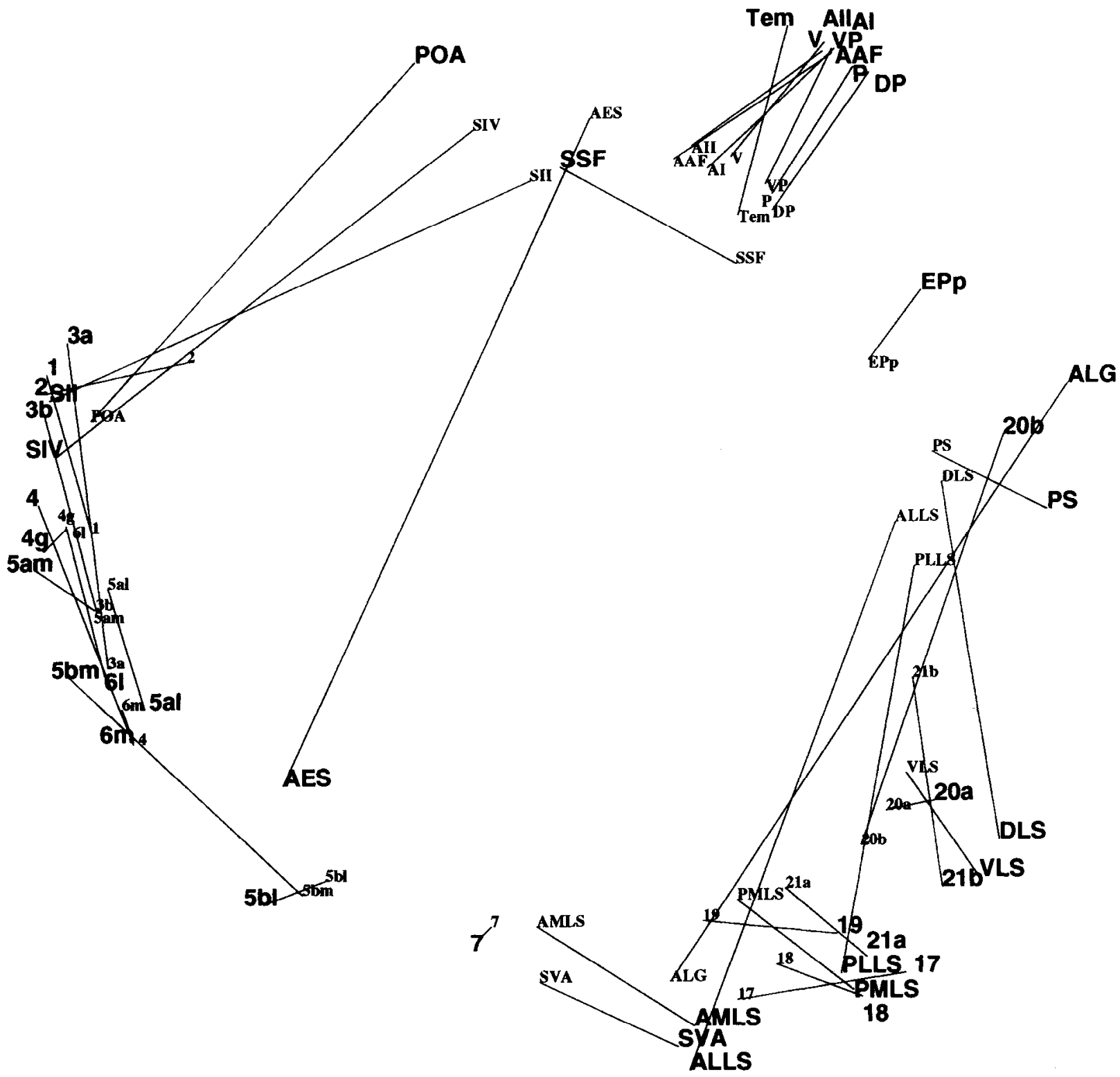

Figure 10. Comparison between the real and next-door-but-one topology of the cat "neocortical" system. The labels in large text show the configuration computed from anatomical connection data (Table 1). The labels in small print show the configuration computed from connections predicted by the "Nearest-neighbor-or-next door but-one" model. Lines are drawn linking the positions or each area in the two solutions, and illustrate the disparity between the real topology and the topology predicted by the model. The "Nearest-neighbor-or-next-door-but-one" configuration explains $68 \%$ of the variance of the real configuration $\left(r^{2}=0.68\right)$, and the relation is significant $(p<0.0016)$.

are known to suffer from this kind of anomaly (Felleman and Van Essen, 1991).

There are several differences between our hierarchical structure shown in Figure 2 and a recent hierarchical arrangement of the cat visual system (Felleman and Van Essen, 1991), which was hased on the anatomical studies of Symmonds and Rosenquist (1984a,b). Felleman and Van Essen (1991) divided the visual areas between eight levels, as opposed to our eleven levels, and there are some differences in the order of areas within the hierarchy. While our hierarchy is based on a larger data set than the previous analysis, we were able to include one more visual area than Felleman and Van Essen (1991).

Analyses of cortical hierarchies that use data on the laminar origin and termination patterns are not based on the area-to-area pattern of connections. Topological structures, on the other hand, are computed from area-to-area connection patterns and do not involve any information about the layers in which connections originate or terminate. Despite this, in all sensory systems so far studied with both techniques (the cat visual, cat auditory, and macaque visual systems; Young, 1992a) corresponding topological and hierarchical structures have been significantly related. Areas that are hierarchically distant from the sensory periphery are also distant from the periphery in terms of their area-to-area connections. It is encouraging that two independent methods of analyzing cortical connection data produce consistent results. If this relation holds, the topological analyses of the major sensory systems of the cat and macaque suggest that all such sensory systems are hierarchically organized.

\section{Neighborhood wiring}

These results provide quantitative support for the idea of a relation between the position of areas on the cortical sheet and 
their connections (Cowey, 1979; Mitchison, 1991; Young, 1992a; Cherniak, 1994). The simple models based on neighborhood wiring connections, particularly nearest-neighbor-or-nextdoor-but-one connections, gave a good account of the gross organization of the connections of the neocortical system (Table 2 ), so the application of such rules during development may be one way in which the genetic information, metabolic costs, and wiring volume needed to build an elaborately connected cerebral cortex are minimized. It should be noted, however, that nearestneighbor-or-next-door-but-one connections produced a topological solution in which the three sensory systems merged more than they may do in reality (Fig. 10); SII and SIV were at positions intermediate to the somatosensory-motor and the auditory systems, for example. The simple models accounted well for the connection pattern within the auditory system, but not so well for the somatosensory-motor or visual systems, and badly for the connections between the dorsal limbic structures and the neocortical areas.

Within the visual, somatosensory and frontolimbic systems, and in the topology of the whole cortex, simple connection models accounted for $30 \%$ or less of the variance of the topological structure derived from real connectivity (Table 2). The particular connections, or lack of connections, that were responsible for the major differences between local connection models and real cortical connectivity were illustrated by the direct matrix comparisons. Major long-range connections, in excess of those predicted by nearest-neighbor-or-next-door-but-one connectivity, link areas 17 and 18 with the lateral suprasylvian visual areas, AES with visual and higher motor areas, and the motor and premotor cortex with area 5, SII, and SIV (Fig. 7).

The sensory systems of the cat are more connectionally isolated from each other than the simple connection rules predict (e.g., Fig. 10). We note two likely explanations. The first explanation is that there may be a genuine sparseness of connections between the cortical systems in the adult animal. Neonatal cortex contains many corticocortical connections that are not present in the adult, these connections being pruned during development (Innocenti and Clark, 1988; Kind and Innocenti, 1990). The failure of the nearest-neighbor-or-next-door-but-one model to produce sharp topological distinctions between the visual, auditory, and somatosensory-motor systems in the solution of the "neocortical" system (Fig. 10) suggests that the adult pattern might be produced by the deletion during development of local connections between bordering areas that respond to different sensory modalities. These deleted connections may correspond to some of the excess nearest-neighbor-or-next-door-but-one connections (black squares in Fig. 8).

The second possible explanation for connectional discontinuities is an experimental bias toward looking for connections within particular cortical systems. Many investigators are visual, somatosensory, or auditory specialists, and it is possible that their studies are focused on the putative cortical system in which they are most interested. Finding global connections is, however, important, both to obtain an unbiased view of the connectivity of the whole cortex and in determining the topological relations of areas within the same sensory system. Scannell and Young (1993) showed that the topological relations of areas can change between the solutions for the isolated sensory systems and the global solution. In the case of the visual areas of the lateral suprasylvian region in the cat, a topological division into the anterior (AMLS and ALLS) and posterior groups (VLS, DLS, PMLS, and PLLS) is revealed only when the global cortical connections are included in the optimization procedure. Consequently, when connection data are used to address questions about the identity and function of cortical areas, connections with as many other structures in the network as possible should be considered.

\section{Appendix}

Areas of the cat cortex used in the cortical parcellation scheme

Here the abbreviation used for the area in the text and figures is followed by the name of each area, and the relation of our parcellation to other relevant anatomical and physiological schemes.

17, area 17, primary visual cortex, or striate cortex (Symonds and Rosenquist, 1984a; Rosenquist, 1985). 18, area 18, a retinotopically organized visual area (Palmer et al., 1978; Tusa et al., 1979; Symonds and Rosenquist, 1984a; Rosenquist, 1985). 19, area 19, a retinotopically organized visual area (Palmer et al., 1978; Tusa et al., 1979; Symonds and Rosenquist, 1984a; Rosenquist, 1985).

PMLS, posteromedial lateral suprasylvian area (Hubel and Wiesel, 1969; Symonds and Rosenquist,1984a; Rosenquist 1985). AMLS, anteromedial lateral suprasylvian area (Palmer et al., 1978; Symonds and Rosenquist, 1984a; Rosenquist, 1985), a visual area in the medial wall of the suprasylvian sulcus. VLS, ventrolateral suprasylviant area (Palmer et al., 1978; Symonds and Rosenquist, 1984a; Rosenquist, 1985; Updyke, 1986), a visual area situated in the posterior wall of the posterior part of the suprasylvian sulcus. PMLS, VLS, and parts of PLLS and AMLS correspond to the Clare-Bishop area of other parcellation schemes (Clare and Bishop, 1954; Sherk, 1986; Grant and Shipp, 1991; Sherk and Mulliganm 1993). PLLS, posterolateral lateral suprasylvian area (Palmer et al., 1978; Symonds and Rosenquist, 1984a; Rosenquist, 1985). ALLS, anterolateral lateral suprasylvian area (Palmer et al., 1978; Symonds and Rosenquist, 1984a; Rosenquist, 1985), a visual area in the lateral wall of the anterior part of the middle suprasylvian sulcus. $D L S$, dorsolateral suprasylvian area, a visual area in the anterior wall of the posterior part of the suprasylvian gyrus (Palmer et al., 1978; Symonds and Rosenquist, 1984a; Rosenquist, 1985; Updyke, 1986). PLLS, ALLS, and DLS overlap with the lateral suprasylvian arca in other parcellation schemes (Sherk, 1986; Grant and, Shipp 1991). We have treated PMLS, PLLS, AMLS, ALLS, VLS, and DLS as separate entities for the collation of connection data, but the precise disposition of visual areas in the lateral suprasylvian cortex remains unclear. There is considerable evidence, however, for several visual areas within lateral suprasylvian sulcus (see Palmer et al., 1978; Komatsu et al., 1983; Blakemore and Zumbroich, 1986; Von Grunau et al., 1986; Zumbroich et al., 1986; Zumbroich and Blakemore, 1987; Gizzi et al., 1990; Toyama et al., 1990; Grant and Shipp, 1991; Bando et al., 1992; Takagi et al., 1992; Yin and Greenwood, 1992a,b; Sherk and Mulligan, 1993).

$21 a$, area $21 \mathrm{a}$, a visual area on the posterior part of the suprasylvian gyrus and the superior wall of the posterior part of the suprasylvian sulcus (Tusa and Palmer, 1980; Symonds and Rosenquist, 1984a; Rosenquist, 1985; Wimbourne and Henry, 1992; Dreher et al., 1993). 21a overlaps with the Clare-Bishop area in the parcellation of Sherk (1986) and Sherk and Mulligan (1993). $21 b$, area $21 \mathrm{~b}$, a visual area on the posterior part of the suprasylvian gyrus and the posterior wall of the posterior part 
of the suprasylvian sulcus (Tusa and Palmer, 1980; Symonds and Rosenquist, 1984a; Rosenquist, 1985). 20a, area 20a, a retinotopically organized visual area on the posterior ectosylvian gyrus (Tusa and Palmer, 1980; Cavada and Reinoso-Suarez, 1983; Symonds and Rosenquist, 1984a; Kuchiiwa et al., 1985; Rosenquist, 1985). $20 \mathrm{~b}$, area $20 \mathrm{~b}$, a retinotopically organized visual area on the posterior ectosylvian gyrus (Tusa and Palmer, 1980; Cavada and Reinoso-Suarez, 1983; Symonds and Rosenquist, 1984a; Kuchiiwa et al., 1985; Rosenquist, 1985; Updyke, 1986).

$A L G$, a visual area located in the lateral wall of the lateral gyrus between areas 7 and 19 (Symonds and Rosenquist, 1984a; Rosenquist, 1985). ALG may be part of area 19 (Heath and Jones, 1971). $\Lambda$ lthough ALG was included in the literature survey and is shown in Figure 1, it was excluded from most of the topological analyses because of the lack of available connectional data.

7 , area 7 , a region of cortex on the middle part of the suprasylvian gyrus, lateral sulcus and lateral gyrus. The area contains cells responsive to visual, auditory, and somatosensory stimuli (Symonds and Rosenquist, 1984a; Rosenquist, 1985; Olson ct al., 1987; Olson and Lawler, 1987; Yin and Greenwood, 1992a), and has been implicated in the control of eye movements (Yin and Greenwood, 1992b).

$A E S$, anterior ectosylvian sulcus, a region of multimodal cortex, containing cells responsive to auditory, visual, and somatosensory stimulation (Symonds and Rosenquist, 1984a; Rosenquist, 1985; Clarey and Irvine, 1986). A large proportion of cells are multimodal (Minciacchetti et al., 1987; Kimura and Tamai, 1992). Dorsoposterior parts of the sulcus are dominated by auditory responsivity, the fundus and ventral bank of the middle part are dominated by visually responsive cells, and the anterodorsal part contains a somatosensory representation (SIV) that is considered as a distinct area in this analysis (Clemo and Stein, 1982, 1984; Minciacchetti et al., 1987; Olson and Graybiel, 1987; Benedek et al., 1988; Clarey and Irvine, 1990a,b; Kimura and Tamai, 1992). AES has strong connections with the superior colliculus and may be involved in oculomotor function (Tamai et al., 1989).

SVA, splenial visual area, situated in the splenial sulcus, between area 17 and the cingulate gyrus (Kalia and Whitteridge, 1973; Symonds and Rosenquist, 1984a; Rosenquist, 1985). SVA may be visually responsive region of the posterior cingulate cortex (Musil and Olson, 1993).

PS, posterior suprasylvian area (Updyke, 1982, 1986; Symonds and Rosenquist, 1984a; Rosenquist, 1985), a retinotopically organized area on the inferior part of the suprasylvian gyrus and sulcus.

$A I$, primary auditory field. $A A F$, anterior auditory field. $P$, posterior auditory field, in the posterior wall of the posterior ectosylvian sulcus. VP, ventroposterior auditory field (Imig and Reale, 1980; Brugge and Reale, 1985; Morel and Imig, 1987; Rouiller et al., 1990). $\mathrm{I}$, AAF, P, and VP, are the "core" auditory fields showing tonotopic organization with narrowly tuned cells (Reale and Imig, 1980; Brugge and Reale, 1985).

$A I I$, second auditory field. $D P$, dorsoposterior auditory field. $V$, ventral auditory field. $S S F$, suprasylvian fringe, a thin band of multimodal cortex running along the inferolateral border of the suprasylvian sulcus. $E P p$, posterior part of the posterior ectosylvian gyrus, a visual and auditory association arca (Bowman and Olson, 1988). Tem, temporal auditory field (Imig and Reale, 1980; Brugge and Reale, 1985; Cavada and Reinoso-Suarez, 1985; Bowman and Olson, 1988; Rouiller et al., 1990). AII, SSF,
EPp, DP, and Tem lie within the "auditory belt." They lack the strict tonotopy of the "core" areas (Brugge and Reale, 1985). The tonotopic organization of AII, for example, is less orderly than that of the "core" auditory fields, and cells within this area exhibit broad tuning curves (Schreiner and Cynader, 1984)

$3 a$, area 3 a. 3 , area 3 b. $l$, area 1. 2, area 2 . These are areas of somatosensory cortex (Hassler and Muhs-Clement, 1964; Dykes and Rasmusson, 1978; Burton and Kopf, 1984; Cavada and Reinoso-Suarez, 1985). 3b, 1, and 2, constitute SI (Iwamura and Tanaka, 1978a,b; Dykes et al., 1980; Felleman et al., 1983), contain one or more somatotopic representations dominated by cells responsive to cutaneous stimulation. $3 \mathrm{~b}, 1$, and 2 may constitute a single somatic koniocortical area (Felleman et al., 1983). 3a contains a single contralateral somatotopic representation dominated by cells responsive to deep stimuli (Dykes et al., 1980; Felleman et al., 1980).

SII, second somatosensory area (Burton et al., 1982; Burton and Kopf, 1984; Cavada and Reinoso-Suarez, 1985), having multiple representations of some body regions (Burton et al., 1982; Clcmo and Stcin, 1984). The majority of cells respond to superficial stimuli. In contrast to the primary somatosensory areas, SII shows a degree of ipsilateral input (Clemo and Stein, 1984; Mori et al., 1989).

SIV, fourth somatosensory area occupying the dorsal bank of the anterior part of the anterior ectosylvian sulcus and adjoining anterior ectosylvian gyrus (Clemo and Stein, 1982, 1984; Burton and Kopf, 1984; Cavada and Reinoso-Suarez, 1985). SIV has an orderly topographic representation of the body surface (Burton et al., 1982; Clemo and Stein, 1984).

$4 g$, area $4 \lambda$ (Avendano and Rausell, 1988); a region of motor cortex that occupies the anterior part of the cruciate sulcus and a small area of surrounding cortex (Pappas and Strick, 1981; Vicario et al., 1983). 4, area 4. This corresponds to areas $4 \mathrm{f}, 4 \mathrm{sf}$, and $4 \partial$ that are in the superior and posterior aspects of the cruciate sulcus (Avendano and Rausell, 1988).

$6 l$, lateral division of area 6 , an area of premotor cortex. This area includes all regions of area 6 lateral to the rostral margin of the cruciate sulcus. It corresponds to the lateral region of area 6a (Avendano and Rausell, 1988). Electrical stimulation in this area may evoke movements (Iwata et al., 1990). $6 \mathrm{~m}$, medial division of area 6 . This area consists of regions of area 6 medial to the rostral margin of the cruciate sulcus and corresponds to the medial part of $6 a \beta, 6 a \alpha$, and 6if (Cavada and Reinoso-Suarez, 1985; Avendano and Rausell, 1988; Musil and Olson, 1991). $6 \mathrm{~m}$ contains a region, the medial frontal eye field, where electrical stimulation may elicit eye movements (Guitton and Mandle 1978; Jeffers and Olson, 1984; Nakai et al., 1986).

$P O A$, presylvian oculomotor areas. These areas are located the medial and lateral walls of the presylvian sulcus and correspond to DLo and VLo (Burton and Kopf, 1984) and to the lateral frontal eye fields (Guitton and Mandle, 1978; Nakai et al., 1986). These two physiologically distinct areas have been considered together because of the relative lack of connectional data. They may be part of area 6 .

$5 \mathrm{am}$, medial part of area $5 \mathrm{a}$ on the medial side of the anterior part of the lateral gyrus and the medial part of the lateral sulcus. $5 \mathrm{al}$, lateral part of area $5 \mathrm{a}$, on the anterior suprasylvian gyrus and lateral side of the lateral sulcus (Avendano and Rausell, 1988). 5a overlaps with SIII, the third somatosensory area (Tanji et al., 1978; Garraghty et al., 1987; Johnson, 1990). 5bm, medial part of area $5 \mathrm{~b}$, on the anterior part of the lateral gyrus and the medial side of the lateral sulcus. $5 b l$, lateral part of area $5 \mathrm{~b}$, on 
the anterior part of the suprasylvian gyrus running into the lateral side of the lateral gyrus. $5 \mathrm{~m}$, medial division of area 5 , on the anterior part of the medial lateral gyrus. SSAo, outer part of suprasylvian sulcal division of area 5 , in the anterior part of the medial wall of the suprasylvian sulcus. SSA $i$, inner (deep) part of suprasylvian sulcal division of area 5 , in the anterior part of the medial wall of the suprasylvian sulcus (Avendano and Rausell, 1988). Area 5 receives somatosensory, visual, and auditory input (Avendano and Rausell, 1988; Olson and Lawler, 1987). $5 \mathrm{~b}$ may be involved in visuomotor integration (Fabre and Buser, 1981), and SSAo and SSAi may have polysensory responsivity (Palmer et al,, 1978).

$P F C$, rostral division of the prefrontal cortex (Cavada and Reinoso-Suarez, 1985). This area overlaps with the dorsal division of prefrontal cortex as defined by Musil and Olson (1988b, 1991). PFCdl, dorsolateral division of the prefrontal cortex (Cavada and Reinoso-Suarez, 1985). $P F C \nu$, ventral division of the prefrontal cortex (Cavada and Reinoso-Suarez, 1985). This area overlaps with both the dorsal and infralimbic divisions of the medial prefrontal cortex of Musil and Olson (1988b, 1991). PFCdm, dorsomedial division of the prefrontal cortex (Cavada and Reinoso-Suarez, 1985). This area overlaps with the dorsal division of the medial prefrontal cortex of Musil and Olson (1988b, 1991).

Ia, agranular insula (Cavada and Reinoso-Suarez, 1985; Guildin et al., 1986). Ig, granular insula (Cavada and Reinoso-Suarez, 1985; Guildin and Markowitsch, 1984; Guildin et al., 1986). The dorsal insula contains a region responsive to visual stimuli, while more ventral insula regions respond to multimodal stimulation (Hicks et al., 1988a,b; Benedek and Hicks, 1988).

$C G a$, anterior part of cingulate cortex (Cavada and ReinosoSuarez, 1985). This corresponds to the anterior part of the posterior cingulate area of Olson and Musil (1992a). CGp, posterior part of cingulate cortex (Olson and Edelstein, 1984; Cavada and Reinoso-Suarez, 1985). This corresponds to the posterior part of the posterior cingulate area of Olson and Musil (1992a). CGa and CGp contain neurons that respond to multimodal sensory stimulation (Olson and Musil, 1992b).

$L A$, anterior limbic cortex (Cavada and Reinoso-Suarez, 1985). This corresponds to the anterior cingulate area of Musil and Olson (1988a, 1991).

$R S$, retrospenial cortex (Cavada and Reinoso-Suarez, 1985).

$P L$, prelimbic area. This corresponds to area 32 (Room et al., 1985; Cavada and Reinoso-Suarez, 1985). This overlaps with the infralimbic division of the medial prefrontal cortex of Musil and Olson (1988b).

$I L$, infralimbic area (Cavada and Reinoso-Suarez, 1985). This corresponds to area 25 of Room et al. (1985).

35 , area 35 of the perirhinal cortex (Cavada and ReinosoSuarez, 1985; Room and Groenewegen, 1986a). 36, area 36 of the perirhinal cortex (Cavada and Reinoso-Suarez 1985; Room and Groenewegen, 1986a).

$P S b$, presubiculum, parasubiculum, and postsubicular cortex (Cavada and Reinoso-Suarez, 1985; Room and Groenewegen, 1986a; Witter and Groenewegen 1986a; 1986b; Witter et al., 1986). Because of the relative lack of connectional data for these areas in the cat, they were considered together in the analysis.

$\mathrm{Sb}$, subiculum (Cavada and Reinoso-Suarez, 1985; Witter et al., 1986; Van Groen et al., 1986).

$E R$, entorhinal cortex (Cavada and Reinoso-Suarez, 1985; Room and Groenewegen, 1986a; Witter et al., 1986; Witter and Groenewegen, 1986a,b).
Hipp, hippocampus proper, including CA1, CA3, excluding the subiculum.

Amyg, amygdala (Krettek and Price, 1977a,b).

\section{References}

Allman J (1990) Evolution of neocortex. In: Cerebral cortex, Vol 8A (Jones EG, Peters A, eds), pp 269-309. New York: Plenum.

Alloway KD, Burton H (1985) Homotypical ipsilateral cortical projections between somatosensory areas 1 and 2 in the cat. Neuroscience $14: 15-35$.

Avendano C, Rausell E (1988) Organization of the association cortical afferent connections of area 5: a retrograde tracer study in the cat. J Comp Neurol 278:1-33.

Babb RS, Waters RS, Asanuma H (1984) Cortico-cortical connections to the motor cortex from the posterior parietal lobe (A5a, A5b, A7) in the cat demonstrated by the retrograde axonal transport of horseradish peroxidase. Exp Brain Res 54:476-486.

Bando T, Takagi M, Toda H, Yoshizawa T (1992) Functional roles of the lateral suprasylvian cortex in ocular near response in the cat. Neurosci Res 15:162-178.

Battaglini PP, Sqatrito S, Galletti C, Maioli MG, Rivera Sanserverino E (1980) Autoradiographic evidence of visual cortical projections to the frontal cortex in the cat. Arch Ital Biol 118:189-195.

Benedek G, Hicks TP (1988) The visual insular cortex of the cat: organization, properties and modality specificity. Prog Brain Res 75: 271-278.

Benedek G, Mucke L, Norita M, Albowitz B, Creutzfeldt OD (1988) Anterior ectosylvian visual area of the cat: physiological properties. Prog Brain Res 75:245-255.

Berson BM, Graybiel AM (1981) Subsystems within the visual association cortex as delineated by their thalamic and cortical affiliations. Prog Brain Res 58:229-238.

Blakemore C, Zumbroich TJ (1987) Stimulus selectivity and functional organization in the lateral suprasylvian visual cortex of the cat. $J$ Physiol (Lond) 389:569 603.

Bowman EM, Olson CR (1988) Visual and auditory association areas of the cat's posterior ectosylvian gyrus: cortical afferents. J Comp Neurol 272:30-42.

Brugge JF, Reale RA (1985) Auditory cortex. In: Cerebral cortex, Vol 4 (Peters A, Jones EG, eds), pp 229-271. New York: Plenum.

Burton H, Kopf EM (1984) Ipsilateral cortical connections from the second and fourth somatic sensory areas in the cat. J Comp Neurol 225:527-533.

Burton H, Mitchell G, Brent D (1982) Second somatic sensory area in the cerebral cortex of cats: somatotopic organisation and cytoarchitecture. J Comp Neurol 210:109-135.

Cavada C (1984) Transcortical sensory pathways to the prefrontal cortex with special attention to the olfactory and visual modalities. In: Cortical integration (Reinoso-Suarez F, Ajmone-Marsan C, eds), pp 317-328. New York: Raven.

Cavada C, Reinoso-Suarez F (1981) Intrahemispheric cortico-cortical afferent connections of the prefrontal cortex in the cat. Brain Res 223:128-133.

Cavada C, Reinoso-Suarez F (1983) Afferent connections of area 20 in the cat studied by means of the retrograde axonal transport of horseradish peroxidase. Brain Res 270:319-324.

Cavada C, Reinuso-Suarez F (1985) Tupographical organization of the cortical afferent connections of the prefrontal cortex in the cat. J Comp Neurol 242:293-324.

Cavada C, Llamas A, Reinoso-Suarez F (1983) Allocortical afferent connections of the prefrontal cortex. Brain Res 260:117-120.

Cherniak C (1994) Component placement optimization and the brain. J Neurosci 14:2418-2427.

Clare MH, Bishop CR (1954) Responses from an association area secondarily activated from optic cortex. J Neurophysiol 17:271-277.

Clarey JC, Irvine DRF (1986) Auditory response properties of neurons in the anterior ectosylvian sulcus of the cat. Brain Res 386:12-19.

Clarey JC, Irvine DRF (1990a) The anterior ectosylvian auditory field in the cat: 1. An electrophysiological study of its relationships to surrounding auditory cortical fields. J Comp Neurol 301:289-303.

Clarey JC, Irvine DRF (1990b) The anterior ectosylvian auditory field in the cat: 2. An HRP study of its connections. J Comp Neurol 310 : 304-324. 
Clemo JR, Stein BE (1982) Somatosensory cortex: a "new" somatotopic representation. Brain Res 235:162-168.

Clemo JR, Stein BE (1984) Organization of a fourth somatosensory area of cortex in cat. $J$ Neurophysiol 50:910-925.

Cowey A (1979) Cortical maps and visual perception. The Grindley memorial lecture. Q J Exp Psychol 31:1-17.

Drcher B, Michalski A, Ho RHT, Lee CWF, Burke W (1993) Processing of form and motion in area 21a of cat visual cortex. Vis Neurosci 10:93-115.

Dykes RW (1978) The anatomy and physiology of the somatic sensory cortical regions. Prog Neurobiol 10:33-88.

Dykes RW, Rasmusson DP, Hoeltzell PB (1980) Organization of primary somatosensory cortex in the cat. J Neurophysiol 43:1527-1546.

Edgington ES (1980) Randomization tests. New York: Dekker.

Fabre M, Buser P (1981) Effects of lesioning the anterior suprasylvian cortex on visuo-motor guidance performance in the cat. Exp Brain Res 41:81-88.

Felleman DJ, Van Essen DC (1991) Distributed hierarchical processing in the primate cerebral cortex. Cereb Cortex 1:1-47.

Felleman DJ, Wall JT, Cusick CG, Kaas JH (1983) The representation of the body surface in S-1 of cats. J Neurosci 3:1648-1669.

Ferrer JMR, Price DJ, Blakemore C (1988) The organization of corticocortical projections from area 17 to area 18 of the cat's visual cortex. Proc R Soc Lond [Biol] 233:77-98.

Garraghty PE, Florence SL, Tenhula WN, Kaas JH (1987) Somatotopic organization of the third somatosensory area (SIII) in cats. Somatosens Res 4:333-357.

Gilbert CD, Kelly JP (1975) The projections of cells in different layers of the cat's visual cortex. J Comp Neurol 163:81-106.

Gizzi MS, Katz E, Schumer RA, Movshon JA (1990) The selectivity for orientation and direction of motion of single neurons in cat striate and extrastriate visual cortex. J Neurophysiol 63:1529-1543.

Gower JC (1971) Statistical methods of comparing different multivariate analyses of the same data. In: Mathematics in the archaenlogical and historical sciences, pp 138-149. Edinburgh: Edinburgh UP.

Grant S, Shipp S (1991) Visuotopic organization of the lateral suprasylvian area and of an adjacent area of the ectosylvian gyrus of the cat cortex: a physiological and connectional study. Vis Neurosci 6:315-388.

Grant S, Shipp S, Wilson RI (1984) Differences in the connectivity of two visual areas within the lateral suprasylvian (LS) complex of the cat visual cortex. J Physiol (Lond) 353:21P.

Graziosi ME, Tucci E, Barbaresi P, Ugolini G, Manzoni T (1982) Cortico-cortical neurones of the somaesthetic area, $\mathrm{S} 1$, as studied in the cat with fluorescent retrograde double labelling.

Guildin WO, Markowitsch HJ (1984) Cortical and thalamic connections of the insular and adjacent cortex of the cat. J Comp Neurol 229:393-418.

Guildin WO, Markowitsch HJ, Lampe R, Irle E (1986) Cortical projections originating from the cat's insular area and remarks on claustro-cortical projections. J Comp Neurol 243:468-487.

Guitton D, Mandle G (1978) Frontal oculomotor area in alert cat. 1. Eye movements and neck activity evoked by stimulation. Brain Res 149:295-312.

Hassler R, Muhs-Clement K (1964) Architectonischer aufbau des sensorimotorischen und parietalen cortex der katze. J Hirnforsch 6:377420.

Heath CJ, Jones EG (1971) The anatomical organization of the suprasylvian gyrus of the cat. Adv Anat Embryol Cell Biol 45:3-64.

Hicks TP, Benedek G, Thurlow GA (1988a) Organization and properties of neurons in a visual area within the insular cortex of the cat. J Neurophysiol 60:397-421.

Hicks TP, Benedek G, Thurlow GA (1988b) Modality specificity of neuronal responses within the cat's insula. J Neurophysiol 60:422437.

Hubel DH, Wiesel TN (1969) Visual areas of the lateral suprasylvian gyrus (Clare-Bishop area) of the Cat. J Physiol (Lond) 202:251-260.

Imig TJ, Reale RA (1980) Patterns of cortico-cortical connections related to tonotopic maps in the cat auditory cortex. J Comp Neurol 192:293-332.

Innocenti GM, Berbel P, Clarke S (1988) Development of projections from auditory to visual areas in the cat. J Comp Neurol 272:242259.

Ino T, Matsuzaki S, Shinonaga Y, Ohishi H, Ogawa-Meguru R, Misuzuno N (1990) Direct projections of non-pyramidal neurons of Am- mon's horn to the amygdala and the entorhinal cortex. Neurosci Lett 115:161-166.

Irle E, Markowitsch HJ (1982) Widespread cortical projections to the hippocampal formation. Neuroscience 17:2637-2647.

Iwamura Y, Tanaka M (1978a) Functional organization of receptive fields in the cat somatosensory cortex. I: Integration within the coronal region. Brain Res 151:49-60.

Iwamura Y, Tanaka M (1978b) Functional organization of receptive fields in the cat somatosensory cortex. II: Second representation of the forepaw in the ansate region. Brain Res 151:61-72.

Iwata K, Muramatsu H, Tsuboi Y, Sumino R (1990) Input-output relationships in the jaw and orofacial motor zones of the cat cerebral cortex. Brain Res 507:337-340.

Jeffers IM, Olson CR (1984) Afferent connections of the cat's medial frontal eye ficld. Soc Neurosci Abstr 10:731.

Johnson JI (1990) Comparative development of somatic sensory cortex. In: Cerebral cortex, Vol 8B (Jones EG, Peters A, eds), pp 335449. New York: Plenum.

Jones EG, Powell TPS (1968) The ipsilateral cortical connexions of the somatic sensory areas in the cat. Brain Res 9:71-94.

Jones EG, Powell TPS (1973) Anatomical organization of the somatosensory cortex. In: Handbook of sensory physiology (Iggo A, ed), pp 579 620. New York: Springer.

Kalia M, Whitteridge D (1973) The visual areas in the splenial sulcus of the cat. J Physiol (Lond) 232:275-283.

Kawamura K (1973a) Corticocortical fiber connections of the cat cerebrum. 1. The temporal region. Brain Res 51:1-21.

Kawamura K (1973b) Corticocortical fiber connections of the cat cerebrum. 2. The parietal region. Brain Res 51:22-40.

Kawamura K (1973c) Corticocortical fiber connections of the cat cerebrum. 3. The occipital region. Brain Res 51:41-60.

Kawamura K, Naito J (1980) Corticocortical neurons projecting to the medial and lateral banks of the middle suprasylvian sulcus in the cat: an experimental study with the horseradish peroxidase method. $J$ Comp Neurol 193:1009-1022.

Kimura A, Tamai Y (1992) Sensory response of cortical neurons in the anterior ectosylvian sulcus, including the area evoking eye movements. Brain Res 575:181-186.

Kind PC, Innocenti GM (1990) The development of cortical projections. In: Systems approaches to developmental neurobiology (Raymond PA, Easter SS Jr, Innocenti GM, eds), pp 113-125. New York: PlenuIn.

Komatsu Y, Katsui S, Keisuke T (1983) Eye movement related cells of the lateral syprasylvian cortex of the cat. Neurosci Lett 41:271276.

Krettek JE, Price JL (1977a) Projections from the amygdaloid complex to the cerebral cortex and thalamus in the rat and cat. J Comp Neurol 172:687-722.

Krettek JE, Price JL (1977b) Projections from the amygdaloid complex and adjacent olfactory structures to the entorhinal cortex and to the subiculum in the rat and the cat. J Comp Neurol 172:723-752.

Kuchiiwa s, Matsue H, Sukakawa K (1985) Efferent connections of area 20 in the cat: WGA-HRP and autoradiographic studies. Exp Brain Res 60:179-183.

Llamas A, Avendano C, Reinoso-Suarez F (1985) Amygdaloid projections to the motor and premotor areas of the cat's cerebral cortex: a topographical study using retrograde transport of horseradish peroxidase. Neuroscience 15:651-657.

Macchi G, Bentivoglio M, Rossini P, Tempesta E (1978) The basolateral amygdaloid projections to the neocortex in the cat. Neurosci Lett 9:347-351.

Maciewicz RJ (1974) Afferents to the lateral suprasylvian gyrus of the cat traced with horseradish peroxidase. Brain Res 78:139-143.

Maunsell JH, Van Essen DC (1983) The connections of the middle temporal visual area (MT) and their relationship to a cortical hierarchy in the macaque monkey. J Neurosci 3:2563-2586.

McNair JL, Avendano C (1980) Cortico-cortical afferents of the motor cortex in the cat. Neurosci Lett [Suppl] 5:110.

Micelli D, Resperant J, Ptito M (1985) Intracortical connections of the anterior ectosylvian and lateral suprasylvian visual areas in the cat. Brain Res 347:291-298.

Minciacchetti D, Tassinari G, Antonini A (1987) Visual and somatosensory integration in the anterior ectosylvian sulcus of the cat. Brain Res 410:21-31. 
Mitchison G (1991) Neuronal branching and the economy of cortical wiring. Proc R Soc Lond [Biol] 245:151-158.

Morel A, Imig T (1987) Thalamic projections to fields AI, A, P, and VP in the cat auditory cortex. J Comp Neurol 265:119-144.

Mori A, Waters RS, Asanuma H (1989) Physiological properties and patterns of projections from the second somatosensory cortex to the motor cortex, area 4g, in the cat. Brain Res 504:206-210.

Mucke L, Norita M, Benedek G, Creutzfeldt O (1982) Physiologic and anatomic investigation of a visual cortical area situated in the ventral bank of the anterior ectosylvian sulcus of the cat. Exp Brain Res 46: $1-11$.

Musil SY, Olson CR (1986) Cortical areas in the medial frontal lobe of the cat. Soc Neurosci Abstr 12:1440.

Musil SY, Olson CR (1988a) Organization of the cortical and subcortical projections to the anterior cingulate cortex in the cat. J Comp Neurol 272:203-218.

Musil Sy, Olson CR (1988b) Organization of the cortical and subcortical projections to the medial prefrontal cortex in the cat. J Comp Neurol 272:219-241.

Musil SY, Olson CR (1991) Cortical areas in the medial frontal lobe of the cat delineated by quantitative analysis of thalamic afferents. $\mathbf{J}$ Comp Neurol 308:457-466.

Musil SY, Olson CR (1993) The role of cat cingulate cortex in sensorimotor integration. In: Neurobiology of cingulate cortex and limbic thalamus: a comprehensive handbook (Vogt BA, Gabriel M, eds), pp 345-365. Boston: Birkhauser.

Nakai M, Tamai Y, Miyashita E (1986) Cortico-cortical connections of the frontal oculomotor areas in the cat. Brain Res 414:91-98.

Nieoullon A, Rispal-Padel L (1976) Somatotopic localization in cat motor cortex. Brain Res 105:405-422.

Norita M, Mucke L, Benedek G, Albowitz B, Katoh Y, Creutzfeldt OD (1986) Connections of the anterior ectosylvian visual area (AEV). Exp Brain Res 62:225-240.

Olson CR, Edelstein S (1984) Afferent connections of the posterior cingulate cortex in the cat. Soc Neurosci Abstr 10:731.

Olson CR, Graybiel AM (1987) The ectosylvian visual area of the cat: location, retinotopic organization and connections. J Comp Neurol 261:277-294

Olson CR, Jeffers IM (1987) Organization of cortical and subcortical projections to area $6 \mathrm{~m}$ in the cat. J Comp Neurol 266:73-94.

Olson CR, Lawler K (1987) Cortical and subcortical afferent connections of a posterior division of feline area 7 (area $7 p$ ). J Comp Neurol 259:13-30.

Olson CR, Musil SY (1992a) Topographic organization of cortical and subcortical projections to posterior cingulate cortex in the cat: evidence for somatic, ocular, and complex subregions. J Comp Neurol 324:237-260.

Olson CR, Musil SY (1992b) Posterior cingulate cortex: sensory and oculomotor properties of single neurons in behaving cat. Cereb Cortex 3:485-502.

Olson CR, Krauzlis RT, Lipkin SM (1987) Areas 7 and 5 in cat: visual and somatosensory responses of single neurons and afferent sensory pathways. Soc Neurosci Abstr 13:628.

Palmer LA, Rosenquist AC, Tusa RJ (1978) The retinotopic organization of the lateral suprasylvian visual areas in the cat. J Comp Neurol 177:237-256.

Pappas CL, Strick PL (1981) Physiological demonstration of multiple representations in the forelimb region of the cat motor cortex. J Comp Neurol 200:481-490.

Paula-Barbossa MM, Feyo PB, Souso-Pinto A (1975) The association connections of the suprasylvian fringe and other areas of the cat auditory cortex. Exp Brain Res 23:535-554.

Payne BR (1992) Evidence for visual cortical area homologues in cat and macaque monkey. Cereb Cortex 3:1-15.

Perez-Bas M, Cavada C, Reinoso-Suarez F (1985) Neocortical afferents to the limbic cortex of the cat. Soc Neurosci Abstr 11:1224.

Porter LL (1991) Patterns of connectivity in the cat sensory-motor cortex: a light and electron microscope analysis of the projections arising from area 3a. J Comp Neurol 312:404-414.

Porter LL, Sakamoto K (1988) Organization and synaptic relationships of the projection from the primary sensory cortex to the primary motor cortex in the cat. J Comp Neurol 271:387-396.

Price DJ (1985) Projections from the visual cortical area 19, the posterior medial lateral suprasylvian area and the lateral posterior-pul- vinar complex of the thalamus to areas 17 and 18 in young kittens Ncurosci Lett 60:363-368.

Price DJ, Blakemore C (1985) The postnatal development of the association cortical projections from visual cortical area 17 to area 18 in the cat. J Neurosci 5:2443-2452.

Price DJ, Zumbroich TJ (1989) Postnatal development of corticocortical efferents from area 17 in the cat's visual cortex. J Neurosei 9:600-613.

Reale RA, Imig TJ (1980) Tonotopic organization in auditory cortex of the cat. J Comp Neurol 192:265-291.

Reinoso-Suarez F (1984) Connection patterns in parieto-temporo-oc cipital association cortex of the feline cerebral cortex. In: Cortical integration (Reinoso-Suarez F, Ajmone-Mersan C, eds), pp 255-278. New York: Raven.

Reinoso-Suarez F, Roda JM (1985) Topographical organization of the cortical afferent connections of the cortex of the anterior ectosylvian sulcus in the cat. Exp Brain Res 59:313-324.

Rockland KS, Pandya DN (1979) Laminar origins and terminations of cortical connections of the occipital lobe in the rhesus monkey. Brain Res 179:3-20.

Room P, Groenewegen HJ (1986a) Connections of the parahippocampal cortex in the cat: 1 . Cortical afferents. J Comp Neurol 251:415 450

Room P, Groenewegen HJ (1986b) Connections of the parahippocampal cortex in the cat: 2. Subcortical afferents. J Comp Neurol 251: $451-473$.

Room P, Russchen FT, Groencwegen HJ, Lohman AIIM (1985) Efferent connections of the prelimbic (area 32) and the infralimbic (area 25) cortices: an autoradiographic tracing study in the cat. J Comp Neurol 242:40-55.

Rosenquist AC (1985) Connections of visual cortical areas in the cat In: Cerebral cortex, Vol 3 (Peters A, Jones EG, eds), pp 255-278. New York: Plenum.

Rouiller EM, Innocenti GM, De Ribaupierre FE (1990) Interconnections of auditory cortical fields of the cat with the cingulate and parahippocampal cortices. Exp Brain Res 80:501-511.

Rouiller EM, Simm GM, Villa AEP, de Ribaupierre Y, de Ribaupierre F (1991) Auditory corticocortical interconnections in the cat: evidence for parallel and hierarchical arrangement of the auditory cortical areas. Exp Brain Res 86:483-505.

Russchen FT (1982) Annggdalopetal projections in the cat: 1. Cortical afferent connections. A study with retrograde and anterograde tracing techniques. J Comp Neurol 206:159-179.

Scannell JW, Young MP (1993) The connectional organization of neural systems in the cat cerebral cortex. Curr Biol 3:191-200.

Scannell JW, Young MP, Blakemore C (1992) Optimization analysis of the connections between areas of the cat cerebral cortex. Soc Neurosci Abstr 18:313.10.

Schonemann P, Carroll RM (1970) Fitting one matrix to another under choice of a similarity transformation and a rigid motion. Psychometrika 35:245-255

Schreiner CE, Cynader MS (1984) Basic functional organization of the second auditory cortical field (AII) of the cat. J Neurophysiol 51: $1284-1305$.

Shepard RN (1962) Multidimensional scaling with an unknown distance function. Psychometrika 27:125-140.

Shepard RN (1980) Multidimensional scaling, tree fitting, and clustering. Science 210:390-398.

Sherk $H$ (1986) Location and connections of visual cortical areas in the cats suprasylvian sulcus. J Comp Neurol 247:1-31.

Sherk H, Mulligan KA (1993) A reassessment of the lower visual field map in striate-recipient lateral suprasylvian cortex. Vis Neurosci 10: $131-158$.

Shipp S, Grant S (1991) Organization of reciprocal connections between area 17 and the lateral suprasylvian area of the cat visual cortex. Vis Neurosci 6:339-355.

Squatrito S, Galletti C, Battaglini PP, Riva Sanserverino E (1981a) An autoradiographic study of bilateral cortical projections from the cat visual areas 18 and 19. Arch Ital Biol 119:1-20.

Squatrito S, Galletti C, Battaglini PP, Riva Sanserverino E (1981b) An autoradiographic study of bilateral cortical projections from cat area 19 and lateral suprasylvian visual area. Arch Ital Biol 119:21-42

Squatrito S, Galletti C, Maioli MG, Battaglini PP (1981c) Cortical visual input to the orbito-insular cortex in the cat. Brain Res 221:7179. 
Symonds LL, Rosenquist AC (1984a) Corticocortical connections among the visual areas in the cat. J Comp Neurol 229:1-38.

Symonds LL, Rosenquist AC (1984b) Laminar origins of visual corticocortical connections in the cat. J Comp Neurol 229:39-47.

Takagi M, Toda H, Yoshizawa T, Hara N, Andoo T, Abe H, Bando T (1992) Ocular convergence-related neuronal responses in the lateral suprasylvian area of alert cats. Neurosci Res 15:229-234.

Takane Y, Young FW, de Leeuw J (1977) Nonmetric individual differences multidimensional scaling: an alternative least squares method with optimal scaling features. Psychometrika 42:7-67.

Tamai Y, Miyashita E, Nakai M (1989) Eye movements following electrical stimulation in the ventral bank of the anterior ectosylvian sulcus in the cat. Neurosci Res 7:159-163.

Tanji DG, Wise SP, Dykes RW, Jones EG (1978) Cytoarchitecture and thalamic connectivity of third somatosensory area of cat cerebral cortex. J Neurophysiol 41:268-284.

Toyama K, Fujii K, Umetani K (1990) Functional differentiation between the anterior and posterior Clare-Bishop cortex of the cat. Exp Brain Res 81:221-233.

Tusa RJ, Palmer LA (1980) Retinotopic organization of areas 20 and 21 in the cat. J Comp Neurol 193:147-164.

Tusa RJ, Rosenquist AC, Palmer LA (1979) Retinotopic Organisation of areas 18 and 19 in the cat. J Comp Neurol 185:657-678.

Ungerleider LG, Mishkin M (1982) Two cortical visual systems In: Analysis of visual behavior (Ingle DG, Goodale MA, Mansfield RJQ, eds), pp 549-586. Cambridge, MA: MIT Press.

Updyke BV (1982) An additional retinotopically organized visual area (PS) within the cat's posterior suprasylvian sulcus and gyrus. Soc Neurosci Abstr 8:810.

Updyke BV (1986) Retinotopic organization within the cat's postcrior suprasylvian sulcus and gyrus. J Comp Neurol 246:26?-280.

Van Groen T, Lopes da Silva FH (1986) Organisation of reciprocal connections between the subiculum and the entorhinal cortex in the cat II. An electrophysiological study. J Comp Neurol 251:111-120.

Van Groen T, Wyss JM (1988) Species differences in hippocampal commissural connections: studies in rat, guinea pig, rabbit, and cat. J Comp Neurol 267:322-344.

Van Groen T, Van Haren FJ, Witter MP, Groenewegen HJ (1986) The organization of reciprocal connections between the subiculum and the entorhinal cortex in the cat: 1 . A neuroanatomical tracing study.

Vedovato M (1978) Identification of afferent connections to cortical area $6 \mathrm{ab}$ in the cat by means of retrograde horseradish peroxidase transport. Neurosci Lett 9:303-310.

Vicario DS, Martin JH, Ghez C (1983) Specialised subregions in the cat motor cortex: a single unit analysis in the behaving animal. Exp Brain Res 51:351-367.

Von Grunau MW, Zumbroich TJ, Poulin C (1987) Visual receptive field properties in the posterior suprasylvian cortex of the cat: a comparison between areas PMLS and PLLS. Vision Res 27:343-356.

Waters RS, Favorov O, Mori A, Asanuma H (1982) Patterns of projections and physiological properties of corticocortical connections from the posterior bank of the ansate sulcus to the motor cortex, area $4 \mathrm{~g}$, of the cat. Exp Brain Res 48:335-344.

Wimbourne BM, Henry GH (1992) Response characteristics of the cells of cortical area $21 \mathrm{a}$ of the cat with special reference to orientation specificity. J Physiol (Lond) 449:457-478.

Winguth SD, Winer JA (1989) Corticocortical connections of the cat primary auditory cortex (A1): laminar organization and identification of supragranular neurons projecting to area A2. J Comp Neurol 248: 36-56.

Witter MP, Groenewegen HJ (1984) Laminar origin and septotemporal distribution of entorhinal and perirhinal projections to the hippocampus in the cat. J Comp Neurol 224:371-385.

Witter MP, Groenewegen HJ (1986a) Connections of the parahippocampal cortex in the cat: 3 . Cortical and thalamic efferents. J Comp Neurol 252:1-31.

Witter MP, Groenewegen HJ (1986b) Connections of the parahippocampal cortex in the cat: 5 . Intrinsic connections; comments on input/ output connections with the hippocampus. J Comp Neurol 252:7894.

Witter MP, Room P, Groenewegen HJ, Lohman AHM (1986) Connections of the parahippocampal cortex in the cat. 5. Intrinsic connection; comments on input-output relationships with the hippocampus. J Comp Neurol 252:78-94.

Yamaguchi K, Massopust LC, Young PA, Horenstein S (1982) Association projections from the second somatosensory cortex in the cat. Acta Anat 112:297-309.

Yin TCT, Greenwood M (1992a) Visual response properties of neurons in the middle and lateral suprasylvian cortices of the behaving cat. Exp Brain Res 88:1-14.

Yin TCT, Greenwood M (1992b) Visuomotor interactions in responses of neurons in the middle and lateral suprasylvian cortices of the behaving cat. Exp Brain Res 88:15-32.

Young FW (1987) In: Multidimensional scaling: history, theory and applications (Hamer RM, ed). Hillside, NJ.

Young FW, Harris DF (1990) In: SPSS base system user's guide (Norusis $M J$, ed). Chicago: SPSS Inc.

Young FW, Takane Y, Lewyckyj R (1978) ALSCAL; a nonmetric multidimensional scaling program with several differences options. Behav Res Methods Instrument 10:451453.

Young MP (1992a) Objective analysis of the topological organization of the primate cortical visual system. Nature 358:152-155.

Young MP (1992b) Optimization analysis of the organization of cortico-cortical connections between areas of the monkey cerebral cortex. Soc Neurosci Abstr 18:313.9.

Young MP (1992c) Optimization analysis of the topological organization of monkey cerebral cortex. Eur J Neurosci [Suppl] 5:160.

Young MP (1993) The organization of neural systems in the primate cerebral cortex. Proc R Soc Lond [Biol] 252:13-18.

Young MP, Scannell JW, Burns APC, Blakemore C (1994) Scaling and brain connectivity. Nature 369:449-450.

Yumiya H, Ghez C (1984) Specialized subregions in the cat motor cortex: anatomical demonstrations of differential projections to rostral and caudal sectors. Exp Brain Res 53:259-276.

Zarzeki P, Shinoda Y, Asanuma H (1978) Projections from area 3a to the motor cortex by neurons activated from group 1 muscle afferents. Exp Brain Res 33:269-282.

Zeki S, Shipp S (1988) The functional logic of cortical connections. Nature 335:311-317.

Zumbroich TJ, Blakemore C (1987) Spatial and temporal selectivity in the suprasylvian visual cortex of the cat. J Neurosci 7:482--500.

Zumbroich TJ, Von Grunau M, Poulin C, Blakemore C (1986) Differences in visual field representation in the medial and lateral banks of the suprasylvian cortex (PMLS/PLLS) of the cat. Exp Brain Res 64: 77-93. 